\title{
Comparison of mental health and subjective quality of life in sexual minority versus heterosexual autistic adults
}

\author{
Goldie A. McQuaid ${ }^{1}$, Justine Gendy ${ }^{2}$, Nancy Raitano Lee ${ }^{3}$, \& Gregory L. Wallace ${ }^{2}$ \\ ${ }^{1}$ Department of Psychology, George Mason University, Fairfax, VA \\ ${ }^{2}$ Department of Speech, Language, and Hearing Sciences, The George Washington University, \\ Washington, DC \\ ${ }^{3}$ Department of Psychological and Brain Sciences, Drexel University, Philadelphia, PA
}

Running title: Autistic adults with sexual minority identities

Corresponding author: Goldie A. McQuaid, Department of Psychology, George Mason University, 4400 University Drive, 3F5 Fairfax, VA 22030, USA.

Email: gmcquaid@gmu.edu

Keywords: autism, anxiety, depression, sexual minority, stress, quality of life 


\begin{abstract}
Background: Although disparities in mental health and subjective quality of life have been reported for autistic adults, reasons for these disparities are poorly understood. A potential factor in these disparities is exposure to social stressors related to minority status (i.e., minority stress), including stigma and discrimination. Autistic individuals are more likely than nonautistic individuals to possess other minority identities, including sexual minority identities. However, to date, few studies have examined whether sexual minority autistic adults experience diminished mental health relative to heterosexual autistic adults, and no research has examined subjective quality of life for sexual minority compared to heterosexual autistic adults.

Methods: Participants were 679 autistic adults aged 18.5 to 83.3 years recruited through Simons Powering Autism Research Knowledge Research Match. Participants completed surveys online, including measures of anxious and depressive symptomatology, perceived stress, and subjective quality of life. Participants reported their sexual orientation and other sociodemographic variables.
\end{abstract}

Results: A large proportion of autistic adults reported a sexual minority identity (43.4\%). Sexual minority autistic adults showed poorer mental health and lower subjective quality of life relative to heterosexual autistic adults. Diminished quality of life in the sexual minority group appears to be driven by the strength of the effects for gay and pansexual compared to heterosexual autistic adults.

Conclusion: Understanding factors that may be related to poorer mental health and decreased subjective quality of life in autistic adults is critical and has been identified as a research priority among autistic stakeholders. The findings reported here underscore the need to examine mental health and subjective quality of life disparities among autistic individuals within 
a societal context, taking into consideration the potential of intersecting minority identities and increased social stressors, as these hold the potential to increase risks for poorer outcome. 


\section{Community brief}

\section{Why is this an important issue?}

Autistic people and sexual minorities separately represent populations at high risk for depression, and anxiety, and for experiencing lower quality of life. Autistic individuals are more likely to identify as a sexual minority. However, there is little research on how the intersection of autism and sexual minority identity may affect mental health and quality of life.

\section{What was the purpose of this study?}

Autistic adults who have a sexual minority identity may be exposed to more minority-related stress. This stress could increase risk for poor outcomes. Thus, we compared heterosexual and sexual minority (like gay, bisexual, asexual) autistic adults to see if having more than one minority identity (that is, an autistic identity and a sexual minority identity) affected mental health or subjective quality of life outcomes.

\section{What did the researchers do?}

We conducted an online study with 679 autistic adults. Autistic adults completed surveys. Participants rated their anxiety, depression and everyday stress. Participants also answered questions about their subjective quality of life, or how satisfied they were with their day-to-day life in a variety of ways. Participants also reported on their sexual orientation, sex assigned at birth and other characteristics. We grouped autistic adults into those who had a sexual minority identity like gay, bisexual, or asexual, and into those who had a heterosexual identity. We 
compared sexual minority and heterosexual autistic adults to see if they differed for mental health or for subjective quality of life.

\section{What were the results of the study?}

Many autistic adults reported a sexual minority identity (43.4\%). Autistic adults with a sexual minority identity reported more depression, anxiety, and stress compared to heterosexual autistic adults. Also, sexual minority autistic adults reported worse subjective quality of life compared to heterosexual autistic adults. Specifically, sexual minority autistic adults reported poorer quality of life in Physical Health, Psychological Health, Environment, and Autism-related quality of life, but not in Social Relationships.

\section{What are the potential weaknesses in the study?}

We did not collect information about specific experiences of minority-related stress. Autistic adults with sexual minority identities may have different experiences with bias, prejudice and discrimination. Understanding these minority-stress experiences would help us better understand why autistic adults who have a sexual minority identity have more mental health problems and poorer subjective quality of life. Also, we did not look at how other minority identities (like racial or gender minority identities) contribute to minority-related stress in sexual minority autistic adults.

\section{How will these findings help autistic adults now or in the future?}

These findings highlight the need for more awareness of sexual minority identities in autistic adults and how these identities could increase exposures to social stressors like stigma and 
discrimination. Understanding the various ways that autistic adults with and without other minority identities are impacted by society's expectations and stereotypes will help us identify ways to improve well-being for all autistic people. 


\section{Introduction}

Mental health problems are common in autistic adults. Compared to the general population, autistic adults are at increased risk for experiencing anxiety disorders ${ }^{1}$ and depression ${ }^{1-3}$ as well as elevated levels of perceived stress. ${ }^{4}$ Autistic adults also report lower levels of subjective quality of life.$^{5-7}$ Poorer subjective quality of life is predicted by increased mental health problems, ${ }^{6,8}$ and mental health problems predict suicidality in autistic individuals. ${ }^{9}$ Importantly, autistic adults are at alarmingly elevated risk for suicidality and completed suicide compared to non-autistic adults. ${ }^{10-12}$ Thus, understanding factors that may be related to increased mental health problems and stress and decreased subjective quality of life in autistic adults is

critical and has been noted as a key research priority by stakeholders in the autism community. ${ }^{13-}$ 16

Because of their neurominority status, autistic individuals may be exposed to a greater number of social stressors. ${ }^{17}$ Minority stress describes excess social stressors that individuals with marginalized identities, including disability status (e.g., autism), experience. ${ }^{18}$ These stressors may include comparison to majority social identities and devaluation of the minoritized identity in the course of this comparison, along with stereotypes, stigma, prejudice and discrimination, which contribute to increased mental health problems among those with minority identities. ${ }^{18}$ In an application of the minority stress model to autism, lower levels of social, psychological and emotional well-being and higher levels of psychological distress in autistic adults were predicted by experiences of minority stress, including everyday discriminatory experiences, events of victimization and discrimination, and the expectation of rejection. ${ }^{17}$ Thus, adverse outcomes in autism may in part be associated with the unique and increased social stressors to which autistic individuals are exposed. 
In addition to their neurominority status, autistic adults may also be more likely to belong to other marginalized groups. For instance, there is emerging evidence that gender and sexual minority identities (e.g., gender identity diversity and sexual orientation diversity) may be more common in autistic than in non-autistic persons. ${ }^{19-22}$ The intersection of neurodiversity with gender and sexual diversity may increase minority stressors experienced by these individuals, and these stressors may contribute to poorer well-being.

Although sexual diversity appears to be more common among autistic relative to nonautistic individuals, to date, most studies have reported on the prevalence of sexual minority identities in autism or have examined these identities within a broader context of sexual knowledge, experiences, and satisfaction. For details on prior studies examining sexual minority identities in autism, see Table $1 .^{21,23-25}$ In the general population, sexual minority adults experience higher levels of mental health problems, ${ }^{26-28}$ suicide risk ${ }^{29}$ and past-year suicidality ${ }^{30}$ compared to heterosexual adults. The intersectionality of minority identities may be associated with unique risks for minority stress. ${ }^{31}$ Thus, greater mental health problems and/or lower subjective quality of life reported for autistic adults may be related to intersecting minority identities, including autism and a sexual minority identity.

Few studies have examined whether autistic adults with sexual minority identities may experience greater mental health problems compared to heterosexual autistic adults. ${ }^{32,33}$ The limited extant research, however, has revealed that sexual and gender minority autistic adults are significantly more likely to self-report a mental health condition (which included mood and anxiety disorders, along with other conditions) compared to heterosexual autistic adults. ${ }^{32}$ When compared to cisgender heterosexual autistic adults, sexual and gender minority autistic adults have elevated rates of mental illness, more physical health problems, and greater exposure to 
health disparities, including barriers in access to care, ${ }^{32}$ an index of quality of life. Only a single study has examined mental health in sexual minority relative to heterosexual autistic adults, and it failed to find differences in these groups ${ }^{34}$ Thus, the limited literature to date presents conflicting findings on whether sexual minority autistic adults experience differences in mental health relative to heterosexual autistic adults. Additionally, to date, no research has examined subjective quality of life in autistic heterosexual and sexual minority adults.

Thus, to address these knowledge gaps, the aim of the current study was to investigate potential mental health and subjective quality of life differences between autistic heterosexual and autistic sexual minority adults. We hypothesized that sexual minority autistic adults would report elevated mental health challenges relative to heterosexual autistic adults. Specifically, we predicted sexual minority individuals would report higher levels of anxious and depressive symptomatology and higher perceived stress. We further hypothesized that compared to heterosexual autistic adults, sexual minority adults would report lower subjective quality of life across all assessed domains.

Studies of non-autistic sexual minority adults examining depression and anxiety ${ }^{34}$ and suicidality ${ }^{30,35}$ suggest that there may be differential risk within sexual minority groups. Thus, follow-up exploratory analyses sought to investigate whether poorer mental health and lower subjective quality of life in sexual minority compared to heterosexual autistic adults may be due to a broader effect of sexual minority status or whether particular sexual minority identities are show differential risks. These analyses scrutinized whether particular sexual minority identities (e.g., gay, bisexual, asexual, pansexual) may be differentially associated with mental health and subjective quality of life outcomes in autism. To this end, we probed potential differences in 
mental health and subjective quality of life between heterosexual and particular sexual minority identities among autistic adults.

\section{Methods}

\section{Participants}

Adult participants were recruited via Simons Powering Autism Research and Knowledge $(\text { SPARK })^{36}$ Research Match as part of a broader online study of autistic adult outcomes. The sample consisted of 679 autistic adults (60.7\% assigned female at birth) aged 18.5 to 83.3 years. All participants were "independent adults," whom SPARK defines as individuals $\geq 18$ years of age who do not have a court-appointed legal guardian and are therefore able to consent for themselves. Based on the criteria used by SPARK to determine "independent adult" status, participants are unlikely to have a co-occurring intellectual disability. Consistent with this, as part of a detailed medical history collected in the present study, no participant reported a cooccurring diagnosis of intellectual disability.

Inclusion criteria for analyses were a self-disclosed community-based professional autism spectrum diagnosis and the completion of all relevant measures. SPARK does not independently confirm self-disclosed autism spectrum diagnoses in participants. Importantly, however, SPARK partners with and recruits from expert autism clinical sites, in part, to increase the likelihood that participants have a professional autism spectrum diagnosis. ${ }^{36}$ A recent study independently confirmed an autism spectrum diagnosis in $98.8 \%$ of a sample of 254 SPARK participants, including "independent" adults, using electronic medical records. This confirms "with high confidence" the validity of reported diagnoses, including self-disclosed autism spectrum diagnoses in SPARK. ${ }^{37}$ Additionally, to characterize the current sample, autistic features were queried using the 28-item Autism-spectrum Quotient (AQ-28). ${ }^{38}$ Consistent with the professional 
community-based autism diagnosis reported by all included participants, $94.8 \%$ of participants scored above the AQ-28 cut-off ( $>65$ ) (see Table 2 ).

The study was approved by The George Washington University Institutional Review board and followed procedures in accordance with the Declaration of Helsinki.

\section{Measures}

Demographics

Socio-demographics data were collected. SPARK independently collected information on participants' sexual orientation. Participants were presented with the question "What is your current sexual orientation?" and could select one of the following nine response options: "heterosexual or straight," "gay or lesbian," "bisexual," "asexual," "pansexual," "queer," “another sexual orientation," "don't know," "prefer not to answer." Participants were also informed that they could skip the question.

In addition to reporting on sexual orientation, participants reported on their sex assigned at birth, gender identity, age, ethno-racial identity, and total annual household income. Given small cell sizes for some racial identities, a binary variable for race was created (non-white, white) and used in analyses, as detailed below.

\section{Depressive symptomatology}

The 9-item Patient Health Questionnaire (PHQ-9) ${ }^{39}$ was used to assess depressive symptomatology and its severity. Participants reported on the presence/frequency of depressive symptomatology over the preceding two-week period using a 4 -point Likert scale $(0=$ Not at all; 1=Several days; $2=$ More than half the days; $3=$ Nearly every day). Responses are summed to 
generate a total score ranging from 0 to 27 . Higher scores are indicative of more severe depressive symptomatology. The PHQ-9 demonstrates criterion and construct validity and high internal reliability (Cronbach's alpha $=0.86-0.89$ ), and test-retest reliability (intraclass correlation=0.84) ${ }^{39}$ Mean PHQ-9 item scores served as a dependent variable in analyses.

\section{Anxious symptomatology}

The 7-item Generalized Anxiety Disorder questionnaire (GAD-7) ${ }^{40}$ was used to assess anxiety symptomatology and severity. Using a 4-point Likert scale $(0=$ Not at all; $1=$ Several days; $2=$ More than half the days; $3=$ Nearly every day), participants reported on the presence/frequency of anxiety during the preceding two weeks. A total score is generated by summing responses. Scores range from 0 to 21 , and higher scores suggest greater anxious symptomatology. The GAD-7 has demonstrated strong criterion and construct validity, high internal consistency (Cronbach's alpha $=0.92$ ) and good test-retest reliability (intraclass correlation $=0.83) .{ }^{40}$ Mean GAD-7 item scores served as a dependent variable in analyses.

\section{Perceived stress}

The Perceived Stress Scale (PSS) ${ }^{41,42}$ is one of the most commonly used instruments for the measurement of perceived stress, and has been implemented in samples of autistic adults..$^{43-45}$ The 10-item version of the PSS was used in the current study. ${ }^{42}$ The PSS forms a unidimensional scale of global perceived stress. Participants respond to each item based on a 5-point Likert scale (ranging from $0=$ Never to $4=$ Very Often). Total scores range from $0-40$, with higher scores indicating greater levels of perceived stress. The 10-item PSS has shown reliability and validity comparable to the longer, 14-item version of the $\mathrm{PSS}^{46}$. Broadly, the 10-item PSS shows good 
reliability (Cronbach's alpha $=0.78-0.98) \cdot{ }^{42,47}$ Further, and of particular relevance to the current study, within a sample of autistic adults without co-occurring intellectual disability, the PSS has demonstrated good reliability (Cronbach's alpha $=.87) .{ }^{44}$ In all analyses, the PSS mean item scores is used as a dependent variable.

\section{Subjective quality of life}

The abbreviated World Health Organization Quality of Life Questionnaire (WHOQOLBREF), ${ }^{48}$ and an autism-specific supplement to the WHOQOL-BREF, the Autism Spectrum Quality of Life (ASQoL) ${ }^{49}$ queried subjective quality of life. The WHOQOL-BREF is a 26-item questionnaire probing four domains of quality of life (QoL): Physical Health (7 items), Psychological Health (6 items), Social Relationships (3 items), and Environment ( 8 items). Items are rated on a 5-point Likert scale (1=Not at all/Very Poor/Very Dissatisfied/Never, 5=Completely/Very Good/Very Satisfied/An extreme amount/Always), and higher scores indicate a higher subjective QoL. Raw domain scores (Physical Health range: 7-35; Psychological Health range: 6-30; Social Relationships range: 3-15; Environment range: 8-40) were used to compute mean item scores for each of the four domains, which served as dependent variables in analyses.

The ASQoL consists of nine items that query subjective QoL. Development of the ASQoL engaged autistic adults to develop "autism-specific" items probing subjective QoL to be administered in conjunction with the WHOQOL-BREF. ${ }^{49}$ Questions are answered on a 5-point Likert scale ( $1=$ Not at All/Never, 5=Totally/Always), and a total ASQoL score is calculated by averaging responses to the initial eight survey items. A final ninth item, which inquires about 'autistic identity,' is not included in the calculation of the total ASQoL score. Mean item scores 
range from 1-5, with higher scores reflecting better subjective autism spectrum QoL. The ASQoL mean score was used as a dependent variable in analyses.

\section{Data analysis}

As detailed below, to maximize statistical power, primary analyses collapsed across specific sexual minority categories (e.g., asexual, bisexual, gay) to examine sexual minority compared to heterosexual individuals (sexual orientation group) on the relevant measures. Participants who selected "don't know" in response to the question on sexual orientation were included in the sexual minority group. Note that in addition to being presented with the response option "prefer not to answer," within the wording of the question itself the following language was included "You may skip this question if you choose not to answer." Thus, participants who responded to the question and who did not select "prefer not to answer" were included in the sexual minority group.

In addition to the main analyses examining sexual orientation group, follow-up exploratory analyses pursued a more fine-grained approach, examining individuals in the larger of the specific sexual minority categories, comparing each of these sexual minority identities to heterosexual individuals.

\section{Demographics}

For the purposes of sample characterization, heterosexual and sexual minority groups were compared for demographic variables, including age, sex assigned at birth, gender identity, ethno-racial identity, and socio-economic status, using independent samples $t$-tests (or the nonparametric equivalent test) or Chi-square tests, as appropriate. 


\section{Mental health}

Analyses of Covariance (ANCOVAs) examined the potential differences in mental health, controlling for age, race, and household income between the heterosexual and sexual minority groups. Three ANCOVAs were conducted, with sexual orientation group (heterosexual vs. sexual minority) as the independent variable and depression symptomatology, anxiety symptomatology, and perceived stress as the dependent variables. Multiple comparisons were controlled for using the false discovery rate (FDR) method, with $q<.05$ considered statistically significant.

\section{Quality of life (QoL)}

Multivariate analysis of covariance (MANCOVA) was used to evaluate potential differences for heterosexual and sexual minority groups on subjective QoL, controlling for age, race, and household income. The independent variable was sexual orientation group (heterosexual vs. sexual minority), and the dependent variables were the mean scores for each of the four WHOQOL-BREF domains (Physical Health, Psychological Health, Social Relationships, Environment) and the mean ASQoL score.

\section{Results}

\section{Demographics}

See Table 2 for descriptive statistics for the sexual minority and heterosexual groups as well as inferential statistical results comparing these two groups on demographics factors. Sexual minority autistic adults were younger than heterosexual autistic adults. Compared to the 
heterosexual group, the sexual minority group had a significantly greater proportion of individuals assigned female at birth (relative to assigned male at birth) and a greater proportion of gender diverse (relative to cisgender) individuals (See Figure S1). Sexual minority autistic adults were more diverse in terms of racial identity, but not ethnic identity. Compared to sexual minority adults, heterosexual adults were more likely to report higher levels of total household income. The heterosexual and sexual minority groups did not significantly differ for autistic features, or in the proportion of individuals meeting the AQ-28 cut-off (>65).

Accounting for demographic differences in primary analyses: Sex assigned at birth

Because sexual orientation groups differed for the proportion of females, the interaction of sex $\times$ sexual orientation group was probed in all models. No significant sexual orientation group $\times$ birth-sex interactions were found $(p s>.05)$ in any of the models. It is important to note that the larger proportion of individuals assigned female at birth in the sexual minority group is consistent with the literature indicating that more autistic individuals assigned female at birth possess a sexual minority identity compared not only to non-autistic females ${ }^{20}$ but also compared to autistic males. ${ }^{19,25,50}$ Thus, given this literature, the focus of the current study (which did not include birth-sex) and no sexual orientation group $\times$ sex interactions in any of the models, we elected not to include birth-sex in the models. However, follow-up exploratory analyses examined the effect of sexual orientation group separately for those assigned female and those assigned male at birth (see Supplement).

Unlike sex assigned at birth, gender identity was not controlled for or examined separately here, given the "overlap" of those with gender diverse and sexual minority identities. 
Of 71 participants reporting a gender diverse identity, $64(90.1 \%)$ report a sexual minority identity while $7(9.9 \%)$ report a heterosexual identity.

\section{Mental health}

ANCOVAs (FDR-corrected, $q<.05$ ) showed that compared to heterosexual autistic adults, sexual minority autistic adults reported significantly more depressive symptomatology $\left(F(1,672)=9.23, q=.007, \eta^{2} p=0.013\right)$, anxious symptomatology $(F(1,672)=3.90, q=.049$, $\left.\eta^{2} \mathrm{p}=0.0058\right)$, and higher perceived stress $\left(F(1,672)=4.0, q=.049, \eta^{2} p=0.006\right)$. See Figure 1 .

\section{Quality of life (QoL)}

Using Pillai's Trace, the MANCOVA revealed a significant main effect of sexual orientation group on QoL $(F(5,668)=5.77, p=0.00003, V=0.04)$. See Figure 2A. Five follow-up ANCOVAs (FDR-corrected, $q<.05$ ) revealed that, compared to heterosexual autistic adults, sexual minority autistic adults reported significantly lower QoL in Physical Health $\left(F(1,672)=23.84, q=.000007, \eta^{2} p=0.03\right)$, Psychological Health $(F(1,672)=12.42, q=.0008$, $\left.\eta^{2} \mathrm{p}=0.01\right)$, and Environment $\left(F(1,672)=14.65, q=.0004, \eta^{2} \mathrm{p}=0.0137\right)$, as well as Autism-related QoL $\left(F(1,672)=7.60, \mathrm{q}=.008, \eta^{2} \mathrm{p}=0.01\right)$. Sexual orientation groups did not differ significantly on the WHOQOL Social Relationships domain $\left(F(1,672)=0.32, q=.57, \eta^{2} p=0.002\right)$.

\section{Exploratory analyses: Sexual minority identities, mental health and QoL}

Where possible, we sought to examine differences in mental health and QoL between specific sexual minority groups and the heterosexual autistic adults. Four of the sexual minority identities had sufficient sample size to detect large effect size differences when compared to the 
heterosexual group. Therefore, using ANCOVAs and a MANCOVA, as in the main analyses examining mental health and subjective QoL, respectively, asexual ( $n=62)$, bisexual $(n=84)$, gay $(n=52)$ and pansexual $(n=44)$ autistic adults were separately compared to heterosexual autistic adults.

\section{Mental health}

In separate comparisons of sexual minority identities (asexual, bisexual, gay, pansexual) with heterosexual autistic adults, no significant differences were found for depressive or anxious symptomatology, or for perceived stress (all $p \mathrm{~s}>.05)$.

\section{Subjective QoL}

Significant differences in subjective QoL were found for autistic gay compared to autistic heterosexual adults and for autistic pansexual compared to autistic heterosexual adults. See Figure 2B. MANCOVAs using Pillai's Trace revealed that compared to heterosexual autistic adults, gay autistic adults showed lower subjective $\operatorname{QoL}(F(5,425)=3.65, p=.003, V=.04)$. Followup ANCOVAs (FDR-corrected, $q<.05$ ) showed that, compared to heterosexual autistic adults, gay autistic adults reported significantly lower QoL in Physical Health $(F(1,429)=8.22, q=.01$, $\left.\eta^{2} \mathrm{p}=0.02\right)$, and Environment $\left(F(1,429)=12.84, q=0.002, \eta^{2} \mathrm{p}=0.02\right)$. Gay and heterosexual autistic adults did not differ significantly on Psychological Health $\left(F(1,429)=2.45, q=.15, \eta^{2} p=0.005\right)$, Social Relationships $\left(F(1,429)=0.38, q=.54, \eta^{2} p=0.002\right)$, or Autism-related QoL $(F(1,429)=2.82$, $\left.q=.15, \eta^{2} \mathrm{p}=0.006\right)$.

Using Pillai's Trace, the MANCOVA revealed that compared to heterosexual autistic adults, pansexual autistic adults showed lower subjective QoL $(F(5,417)=4.45, p=0.0006$, 
$V=0.05$ ). Follow-up ANCOVAs (FDR-corrected, $q<.05$ ) showed that, compared to heterosexual autistic adults, pansexual autistic adults reported significantly lower QoL in Physical Health $\left(F(1,421)=13.90, q=.001, \eta^{2} \mathrm{p}=0.03\right)$, and Psychological Health $(F(1,421)=6.85, q=.02$, $\left.\eta^{2} p=0.01\right)$. Pansexual and heterosexual groups did not differ significantly on Environment $\left(F(1,421)=2.15, q=.21, \eta^{2} \mathrm{p}=0.003\right)$, Social Relationships $\left(F(1,421)=0.44, q=.51, \eta^{2} \mathrm{p}=0.0002\right)$, or Autism-related QoL $\left(F(1,421)=1.93, q=.21, \eta^{2} \mathrm{p}=0.006\right)$.

MANCOVAs showed no significant main effect of asexual versus heterosexual $(F(5,435)=1.88, p=.097, V=.02)$ or for bisexual versus heterosexual $(F(5,457)=2.12, p=.06$, $V=.02$ ) autistic adults on subjective QoL.

\section{Discussion}

We report on mental health symptomatology and subjective quality of life (QoL) in autistic adults with and without a sexual minority identity. Consistent with previous studies reporting a high prevalence of sexual minority identities in autistic samples, ${ }^{19,21,23-25,51}$ a large proportion of autistic adults in the current study identified as a sexual minority (43.4\%). This is in comparison with $\sim 4 \%$ of the general population in the US who report a sexual minority identity $^{52,53}$. Extending prior research, we found elevated anxious and depressive symptomatology, as well as higher levels of perceived stress, in sexual minority relative to heterosexual autistic adults. In a novel finding, we further report that sexual minority autistic adults evidence lower subjective QoL across multiple domains when compared to heterosexual autistic adults. Finally, in exploratory follow-up analyses in which we separately compared larger subgroups of sexual minority with heterosexual autistic adults, we found that gay and 
pansexual sexual minority groups appear to be driving subjective QoL findings reported in the main analyses.

Independent research has demonstrated that autistic adults are at increased risk (relative to the general population) for developing anxiety ${ }^{1}$ and depression, ${ }^{1-3}$ experiencing suicidal ideation/suicidality ${ }^{3}$, and for death by suicide. ${ }^{10-12}$ Studies of non-autistic individuals show that sexual minority individuals, relative to heterosexual individuals, have increased mental health problems, including elevated perceived stress, ${ }^{57}$ anxiety, ${ }^{28,29}$ depression ${ }^{28,29}$. Given that sexual minority identities are more common in autistic than in non-autistic individuals, it was critically important to examine potential additive impacts of sexual minority identity in autistic adults. Accordingly, we hypothesized that autistic sexual minority adults would experience greater anxious and depressive symptomatology and higher levels of perceived stress relative to heterosexual autistic adults. These hypotheses were confirmed. Furthermore, when we investigated mental health in autistic sexual orientation groups separately by birth-sex, the effect sizes of these results were comparable to those reported in the main analyses. The results reported here are aligned with prior studies in which sexual minority autistic adults reported greater health disparities relative to heterosexual autistic individuals, including more mental health problems. ${ }^{32}$ However, our results contrast with a single study examining mental health symptomatology in sexual minority relative to heterosexual autistic adults, which did not find a difference in mental health when comparing sexual minority and heterosexual autistic adults. ${ }^{33}$ Important differences between this previous study and the current study may account for the discrepancy in findings. These differences include a larger sample size in the current study, providing for increased statistical power to detect effects of smaller magnitude. 
In a novel hypothesis, we further predicted that autistic adults with a sexual minority identity would report lower subjective QoL compared to heterosexual autistic adults. This prediction was confirmed: sexual minority autistic adults reported lower subjective QoL across domains, with the exception of Social Relationships. Specifically, sexual minority autistic adults reported lower levels of Physical Health, Psychological Health, Environment, and Autismrelated subjective QoL. We additionally investigated subjective QoL in sexual orientation groups separately by birth-sex, and effect sizes of these results were comparable to those reported in the main analyses. Although prior research has not investigated how QoL is impacted by sexual minority identities in autism, our findings are consistent with unrelated, parallel research pointing to poorer quality of life outcomes in sexual minority (relative to heterosexual) nonautistic adults ${ }^{57}$ Finally, exploratory follow-up analyses suggested that these lower QoL findings in sexual minority autistic adults were driven by pansexual and gay identities, a novel finding that requires replication and more detailed examination.

Minority stress models point out that disparities in outcomes among marginalized populations do not occur in a vacuum; rather, they are embedded within a societal context, in which persons can be centered and valued or marginalized and devalued, and in which stereotypes and stigma exert influences on those deemed to be the "other." 18 A key component of minority stress models considers effects of 'concealment,' whereby a stigmatized identity is not disclosed, is concealed, or where there may be various levels of "outness" (e.g., out to everyone, or out to a small group with whom one feels insulated from discrimination). ${ }^{18}$

Concealment may be a particularly important component of the minority stress model to consider within autistic samples ${ }^{17}$ for two reasons. First, a relatively large proportion of autistic individuals also possess a sexual minority identity. Second, concealment may share features with 
some facets of "camouflaging." Camouflaging includes behaviors that may "conceal" one's autistic identity, ${ }^{58,59}$ and is associated with risk for anxiety, ${ }^{60}$ depression, ${ }^{61}$ and suicidality. ${ }^{62}$ Some autistic adults report camouflaging in order to "pass" as neurotypical, and to avoid bullying and harassment; ${ }^{63}$ thus, masking one's autistic identity may be one response to stigma. ${ }^{64}$ Future studies should endeavor to understand concealment and camouflaging among autistic individuals with sexual minority (and/or other minority) identities. These studies should interrogate how possessing intersecting stigmatized identities and potentially greater exposure to social stressors may drive concealment and camouflaging. Such research should further examine whether and how concealing more than one minority identity may contribute to disparities in mental health and subjective QoL in autistic individuals.

Strengths of the current study include the examination of mental health and subjective QoL in a large sample of autistic adults spanning a large age range, from early to late adulthood. Additionally, in order to carefully scrutinize sexual minority identity, given that it has been understudied in the literature despite being overrepresented in autistic individuals, we controlled for certain potentially confounding factors. In particular, we controlled for factors that may have differential impacts on mental health and subjective QoL, namely: age, racial identity, and socioeconomic status. Also, differing from previous studies, ${ }^{23,32}$ we examined sexual orientation on its own and did not collapse across individuals reporting sexual minority identities and those reporting gender minority identities. This focus on mental health and subjective QoL in sexual minority autistic adults specifically is important, as sexual minority and gender minority individuals may experience different social stressors related to their respective minority identities. 
However, this study also had limitations. We were not able to directly query participants' experiences of bias, stigma, prejudice and discrimination. Not all autistic adults with a sexual minority identity will have identical experiences of minority stress, and intrapersonal factors (e.g., personality traits, coping abilities, and resilience) and interpersonal factors (e.g., how supportive and accepting one's milieu is) may impact the experiences of minority stress ${ }^{18}$ and thus whether and to what degree this stress confers risks for poorer outcomes. Thus, to better understand how differences in the experiences of social stressors themselves affect mental health and subjective QoL, future studies should examine sexual minority identities in autistic individuals to query their lived experience of minority stress.

Additionally, studies should probe how other minority identities (e.g., minority ethnoracial and gender identities) may add to social stressors for autistic adults who possess a sexual minority identity. In the non-autistic population, more ethno-racial minorities identify as sexual minorities, and overall growth in those in the US identifying as a sexual minority from 2012 to 2017 was driven, in part, by increased identification as a sexual minority among ethno-racial minorities. ${ }^{52}$ A 2017 report showed that while $33 \%$ of the general population report their ethnoracial identity as non-white and non-Latinx, ethno-racial minorities account for $40 \%$ of individuals identifying as sexual minorities. ${ }^{52}$ This is consistent with the current study, which found a greater proportion of non-white autistic adults in the sexual minority group compared to the heterosexual group. Thus, some of the sexual minority individuals in the current study may experience additional social stressors related to their minority racial identity. These added social stressors may in turn exacerbate risks for mental health problems and poorer QoL. Future studies should aim to understand whether or not this is the case, and if it is, whether the contribution of 
minority stress related to racial identity has an additive (or super-additive) effect on mental health and subjective QoL.

Given increasingly robust evidence that sexual minority identities are more common in autistic than non-autistic individuals, the current study supports the idea that examining intersecting marginalized identities and minority stress in autistic persons is critical to informing our understanding of mental health and QoL disparities in autism. Autistic adults and other central stakeholders in the autism community have set mental health and QoL as key research priorities $^{15,16}$, thus lending weight to the importance and value of the findings reported here.

\section{Authorship Confirmation Statement}

All authors contributed to the conception of this study. G.L.W. and N.L.R. contributed data for analysis. G.A.M conducted data analysis. G.A.M., J.G., N.L.R. and G.L.W. conducted interpretation of results. All authors revised the article and approved of the final version for publication. The article has been submitted solely to this journal and is not published, in press, or submitted elsewhere.

\section{Acknowledgments}

We wish to express our gratitude to all of the families in SPARK, the SPARK clinical sites, and SPARK staff. We appreciate obtaining access to recruit participants through SPARK research match on SFARI Base.

\section{Author Disclosure Statement}

No author has any potential conflicts to declare. 


\section{Funding Information}

This research was supported by an Autism Speaks Postdoctoral Fellowship (Grant ID 11808) to G.A.M., and by start-up funds from The George Washington University to G.L.W. 


\section{References}

1. Hollocks MJ, Lerh JW, Magiati I, Meiser-Stedman R, Brugha TS. Anxiety and depression in adults with autism spectrum disorder: A systematic review and meta-analysis. Psychol Med. 2019;49(4):559-572. doi:10.1017/S0033291718002283

2. Hudson CC, Hall L, Harkness KL. Prevalence of depressive disorders in individuals with autism spectrum disorder: A meta-analysis. J Abnorm Child Psychol. March 2018:1-11. doi:10.1007/s10802-018-0402-1

3. Hedley D, Uljarević M, Wilmot M, Richdale A, Dissanayake C. Brief report: Social support, depression and suicidal ideation in adults with autism spectrum disorder. $J$ Autism Dev Disord. 2017;47(11):3669-3677. doi:10.1007/s10803-017-3274-2

4. Bishop-Fitzpatrick L, Mazefsky CA, Minshew NJ, Eack SM. The relationship between stress and social functioning in adults with autism spectrum disorder and without intellectual disability. Autism Res. 2015;8(2):164-173. doi:https://doi.org/10.1002/aur.1433

5. Tobin MC, Drager KDR, Richardson LF. A systematic review of social participation for adults with autism spectrum disorders: Support, social functioning, and quality of life. Res Autism Spectr Disord. 2014;8(3):214-229. doi:10.1016/j.rasd.2013.12.002

6. Mason D, McConachie H, Garland D, Petrou A, Rodgers J, Parr JR. Predictors of quality of life for autistic adults. Autism Res. 2018;11(8):1138-1147. doi:https://doi.org/10.1002/aur.1965

7. van Heijst BFC, Geurts HM. Quality of life in autism across the lifespan: A meta-analysis. Autism. 2014;19(2):158-167. doi:10.1177/1362361313517053

8. Smith IC, Ollendick TH, White SW. Anxiety moderates the influence of ASD severity on 
quality of life in adults with ASD. Res Autism Spectr Disord. 2019;62:39-47.

doi:https://doi.org/10.1016/j.rasd.2019.03.001

9. Jokiranta-Olkoniemi E, Gyllenberg D, Sucksdorff D, et al. Risk for premature mortality and intentional self-harm in autism spectrum disorders. J Autism Dev Disord. November 2020:1-11. doi:10.1007/s10803-020-04768-x

10. Hirvikoski T, Mittendorfer-Rutz E, Boman M, Larsson H, Lichtenstein P, Bölte S. Premature mortality in autism spectrum disorder. Br J Psychiatry. 2016;208(03):232-238. doi:10.1192/bjp.bp.114.160192

11. Kõlves K, Fitzgerald C, Nordentoft M, Wood SJ, Erlangsen A. Assessment of suicidal behaviors among individuals with autism spectrum disorder in Denmark. JAMA Netw Open. 2021;4(1):e2033565. doi:10.1001/jamanetworkopen.2020.33565

12. South M, Costa AP, McMorris C. Death by suicide among people with autism: Beyond Zebrafish. JAMA Netw Open. 2021;4(1):e2034018-e2034018. doi:10.1001/jamanetworkopen.2020.34018

13. Autistic Adults and other Stakeholders Engage Together (AASET). Year 1 Meeting Executive Summary.; 2017.

14. International Society for Autism Research (INSAR). Autism Community Priorities for Suicide Prevention: An International Society for Autism Research Policy Brief.; 2021.

15. Benevides TW, Shore SM, Palmer K, et al. Listening to the autistic voice: Mental health priorities to guide research and practice in autism from a stakeholder-driven project. Autism. 2020;24(4):822-833. doi:10.1177/1362361320908410

16. Benevides TW, Cassidy SA. Measuring what matters in autism research and practice. Autism in Adulthood. 2020;2(1):1-3. doi:10.1089/aut.2020.29009.twb 
17. Botha M, Frost DM. Extending the minority stress model to understand mental health problems experienced by the autistic population. Soc Ment Health. 2020;10(1):20-34. doi:10.1177/2156869318804297

18. Meyer IH. Prejudice, social stress, and mental health in lesbian, gay, and bisexual populations: Conceptual issues and research evidence. Psychol Bull. 2003;129(5):674697. doi:10.1037/0033-2909.129.5.674

19. Dewinter J, De Graaf H, Begeer S. Sexual orientation, gender identity, and romantic relationships in adolescents and adults with autism spectrum disorder. J Autism Dev Disord. 2017;47(9):2927-2934. doi:10.1007/s10803-017-3199-9

20. George R, Stokes MA. Gender identity and sexual orientation in autism spectrum disorder. Autism. 2018;22(8):970-982. doi:10.1177/1362361317714587

21. Weir E, Allison C, Baron-Cohen S. The sexual health, orientation, and activity of autistic adolescents and adults. Autism Res. 2021;14(11):2342-2354. doi:https://doi.org/10.1002/aur.2604

22. Warrier V, Greenberg DM, Weir E, et al. Elevated rates of autism, other neurodevelopmental and psychiatric diagnoses, and autistic traits in transgender and gender-diverse individuals. Nat Commun. 2020;11(1):1-12. doi:10.1038/s41467-02017794-1

23. Pecora LA, Hancock GI, Hooley M, et al. Gender identity, sexual orientation and adverse sexual experiences in autistic females. Mol Autism. 2020;11(1):57. doi:10.1186/s13229020-00363-0

24. Pecora LA, Hancock GI, Mesibov GB, Stokes MA. Characterising the sexuality and sexual experiences of autistic females. J Autism Dev Disord. 2019;49(12):4834-4846. 
doi:10.1007/s10803-019-04204-9

25. Gilmour L, Schalomon PM, Smith V. Sexuality in a community based sample of adults with autism spectrum disorder. Res Autism Spectr Disord. 2012;6(1):313-318. doi:https://doi.org/10.1016/j.rasd.2011.06.003

26. Cochran SD, Sullivan JG, Mays VM. Prevalence of mental disorders, psychological distress, and mental health services use among lesbian, gay, and bisexual adults in the United States. J Consult Clin Psychol. 2003;71(1):53-61. doi:10.1037/0022-006X.71.1.53

27. Akré E-R, Anderson A, Stojanovski K, Chung KW, VanKim NA, Chae DH. Depression, anxiety, and alcohol use among LGBTQ+ people during the COVID-19 pandemic. Am J Public Health. 2021;111(9):1610-1619. doi:10.2105/AJPH.2021.306394

28. Borgogna NC, McDermott RC, Aita SL, Kridel MM. Anxiety and depression across gender and sexual minorities: Implications for transgender, gender nonconforming, pansexual, demisexual, asexual, queer, and questioning individuals. Psychol Sex Orientat Gend Divers. 2019;6(1):54-63. doi:10.1037/sgd0000306

29. Horwitz AG, Berona J, Busby DR, et al. Variation in suicide risk among subgroups of sexual and gender minority college students. Suicide Life-Threatening Behav. 2020;50(5):1041-1053. doi:https://doi.org/10.1111/sltb.12637

30. Ramchand R, Schuler MS, Schoenbaum M, Colpe L, Ayer L. Suicidality among sexual minority adults: Gender, age, and race/ethnicity differences. Am J Prev Med. 2021. doi:https://doi.org/10.1016/j.amepre.2021.07.012

31. Crenshaw K. Demarginalizing the intersection of race and sex: A black feminist critique of antidiscrimination doctrine, feminist theory and antiracist politics. $u$ Chi Leg $f$. 1989:139-167. 
32. Hall JP, Batza K, Streed CG, Boyd BA, Kurth NK. Health disparities among sexual and gender minorities with autism spectrum disorder. J Autism Dev Disord. 2020;50:30713077.

33. George R, Stokes MA. A quantitative analysis of mental health among sexual and gender minority groups in ASD. J Autism Dev Disord. 2018;48(6):2052-2063. doi:10.1007/s10803-018-3469-1

34. Ross LE, Salway T, Tarasoff LA, MacKay JM, Hawkins BW, Fehr CP. Prevalence of depression and anxiety among bisexual people compared to gay, lesbian, and heterosexual individuals: A systematic review and meta-analysis. J Sex Res. 2018;55(4-5):435-456. doi:10.1080/00224499.2017.1387755

35. Salway T, Ross LE, Fehr CP, et al. A systematic review and meta-analysis of disparities in the prevalence of suicide ideation and attempt among bisexual populations. Arch Sex Behav. 2019;48(1):89-111. doi:http://dx.doi.org/10.1007/s10508-018-1150-6

36. The SPARK Consortium. SPARK: A US cohort of 50,000 families to accelerate autism research. Neuron. 2018;97(3):488-493. doi:10.1016/j.neuron.2018.01.015

37. Fombonne E, Coppola L, Mastel S, O’Roak BJ. Validation of autism diagnosis and clinical data in the SPARK cohort. J Autism Dev Disord. 2021. doi:10.1007/s10803-02105218-y

38. Hoekstra RA, Vinkhuyzen AAE, Wheelwright S, et al. The construction and validation of an abridged version of the Autism-Spectrum Quotient (AQ-Short). J Autism Dev Disord. 2011;41(5):589-596. doi:10.1007/s10803-010-1073-0

39. Kroenke K, Spitzer RL, Williams JBW. The PHQ-9: Validity of a brief depression severity measure. J Gen Intern Med. 2001;16(9):606-613. doi:10.1046/j.1525- 
1497.2001.016009606.x

40. Spitzer RL, Kroenke K, Williams JBW, Löwe B. A brief measure for assessing generalized anxiety disorder: The GAD-7. Arch Intern Med. 2006;166(10):1092-1097. doi:10.1001/archinte.166.10.1092

41. Cohen S, Kamarck T, Mermelstein R. A global measure of perceived stress. J Health Soc Behav. 1983;24(4):385-396. doi:10.2307/2136404

42. Cohen S, Williamson G. Perceived stress in a probability sample of the US. In: Spacapam S, Oskamp S, eds. The Social Psychology of Health: Claremont Symposium on Applied Social Psychology. Newburgy Park, CA: Sage; 1988.

43. Bishop-Fitzpatrick L, Mazefsky CA, Eack SM. The combined impact of social support and perceived stress on quality of life in adults with autism spectrum disorder and without intellectual disability. Autism. 2017;22(6):703-711. doi:10.1177/1362361317703090

44. Bishop-Fitzpatrick L, Minshew NJ, Mazefsky CA, Eack SM. Perception of life as stressful, not biological response to stress, is associated with greater social disability in adults with autism spectrum disorder. J Autism Dev Disord. 2017;47(1):1-16. doi:10.1007/s10803-016-2910-6

45. Wijker C, Leontjevas R, Spek A, Enders-Slegers M-J. Effects of dog assisted therapy for adults with autism spectrum disorder: An exploratory randomized controlled trial. $J$ Autism Dev Disord. 2020;50(6):2153-2163. doi:10.1007/s10803-019-03971-9

46. Roberti JW, Harrington LN, Storch EA. Further psychometric support for the 10-Item version of the perceived stress scale. J Coll Couns. 2006;9(2):135-147. doi:https://doi.org/10.1002/j.2161-1882.2006.tb00100.x

47. Cohen S, Janicki-Deverts D. Who's stressed? Distributions of psychological stress in the 
United States in probability samples from 1983, 2006, and 2009. J Appl Soc Psychol.

2012;42(6):1320-1334. doi:https://doi.org/10.1111/j.1559-1816.2012.00900.x

48. The WHOQOL Group. Development of the World Health Organization WHOQOL-BREF Quality of Life Assessment. Psychol Med. 1998;28(3):551-558. doi:DOI:

$10.1017 / \mathrm{S} 0033291798006667$

49. McConachie H, Mason D, Parr JR, Garland D, Wilson C, Rodgers J. Enhancing the validity of a quality of life measure for autistic people. J Autism Dev Disord. 2018;48(5):1596-1611. doi:10.1007/s10803-017-3402-z

50. Bejerot S, Eriksson JM. Sexuality and gender role in autism spectrum disorder: A case control study. PLoS One. 2014;9(1). doi:10.1371/journal.pone.0087961

51. Bush HH. Dimensions of sexuality among young women, with and without autism, with predominantly sexual minority identities. Sex Disabil. 2019;37(2):275-292. doi:10.1007/s11195-018-9532-1

52. Gates GJ. In U.S., More Adults Identifying as LGBT.; 2017. https://news.gallup.com/poll/201731/lgbt-identification-rises.aspx.

53. Medley G, Lipari RN, Bose J, Cribb DS, Kroutil LA, McHenry G. Sexual Orientation and Estimates of Adult Substance Use and Mental Health: Results from the 2015 National Survey on Drug Use and Health.; 2016.

54. Hottes TS, Bogaert L, Rhodes AE, Brennan DJ, Gesink D. Lifetime prevalence of suicide attempts among sexual minority adults by study sampling strategies: A Systematic review and meta-analysis. Am J Public Health. 2016;106(5):e1-e12.

doi:10.2105/AJPH.2016.303088

55. Plöderl M, Tremblay P. Mental health of sexual minorities: A systematic review. Int Rev 
Psychiatry. 2015;27(5):367-385. doi:10.3109/09540261.2015.1083949

56. Krueger EA, Meyer IH, Upchurch DM. Sexual orientation group differences in perceived stress and depressive symptoms among young adults in the United States. LGBT Heal. 2018;5(4):242-249. doi:10.1089/lgbt.2017.0228

57. Austin SB, Gordon AR, Ziyadeh NJ, Charlton BM, Katz-Wise SL, Samnaliev M. Stigma and health-related quality of life in sexual minorities. Am J Prev Med. 2017;53(4):559566. doi:10.1016/j.amepre.2017.05.007

58. Attwood T. The Complete Guide to Asperger's Syndrome. Jessica Kingsley Publishers; 2007.

59. Hull L, Petrides K V., Allison C, et al. "Putting on my best normal": Social camouflaging in adults with autism spectrum conditions. J Autism Dev Disord. 2017;47(8):2519-2534. doi:10.1007/s10803-017-3166-5

60. Livingston LA, Colvert E, Bolton P, Happé F, Happé F. Good social skills despite poor theory of mind: exploring compensation in autism spectrum disorder. J Child Psychol Psychiatry. 2019;60(1):102-110. doi:10.1111/jcpp.12886

61. Cage E, Di Monaco J, Newell V. Experiences of autism acceptance and mental health in autistic adults. J Autism Dev Disord. 2018;48(2):473-484. doi:10.1007/s10803-017-33427

62. Cassidy S, Bradley L, Shaw R, Baron-Cohen S. Risk markers for suicidality in autistic adults. Mol Autism. 2018;9(1):42. doi:10.1186/s13229-018-0226-4

63. Cage E, Troxell-Whitman Z. Understanding the reasons, contexts and costs of camouflaging for autistic adults. J Autism Dev Disord. 2019;49(5):1899-1911. doi:10.1007/s10803-018-03878-x 
64. Pearson A, Rose K. A conceptual analysis of autistic masking: Understanding the narrative of stigma and the illusion of choice. Autism in Adulthood. 2021;3(1):52-60. doi:10.1089/aut.2020.0043

65. Bush HH, Williams LW, Mendes E. Brief Report: Asexuality and young women on the autism spectrum. J Autism Dev Disord. 2021;51(2):725-733. doi:10.1007/s10803-02004565-6 
Table 1. Quantitative studies examining sexual minority identities in autistic individuals

\begin{tabular}{|c|c|c|c|c|c|c|c|c|}
\hline 总 & $\begin{array}{l}\text { Participant } \\
\text { groups, } N s\end{array}$ & $\begin{array}{l}\text { Age, years } \\
\text { Mean (SD), } \\
\text { Range }\end{array}$ & $\begin{array}{l}\text { Sex assigned at } \\
\text { birth }(F / M)\end{array}$ & Gender identity & $\begin{array}{l}\text { Aims/Research } \\
\text { questions related } \\
\text { to sexual } \\
\text { orientation }\end{array}$ & $\begin{array}{l}\text { Methods \& } \\
\text { measures }\end{array}$ & $\begin{array}{l}\text { How Sexual orientation } \\
\text { assessed \& reporting of } \\
\text { sexual orientations }\end{array}$ & Relevant findings \\
\hline 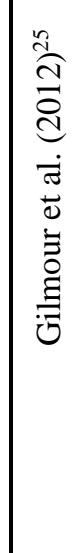 & $\begin{array}{l}\text { Autistic } \\
82 \\
\text { Non-autistic } \\
282\end{array}$ & $\begin{array}{l}\text { Autistic } \\
28.9(9.3) \\
\\
\text { Non-autistic } \\
23.2(7.3)\end{array}$ & $\begin{array}{l}\text { Autistic } \\
27 / 55 \\
\\
\text { Non-autistic } \\
180 / 102\end{array}$ & Not reported & $\begin{array}{l}\text {-Compare sexual } \\
\text { knowledge \& } \\
\text { experiences of } \\
\text { autistic and non- } \\
\text { autistic adults }\end{array}$ & $\begin{array}{l}\text { Online surveys } \\
\text { - Autism Quotient } \\
\text { (AQ) } \\
\text { - Trotter and } \\
\text { Alderson's Sexual } \\
\text { Experience } \\
\text { Questionnaire } \\
\text { - Sexual vocabulary } \\
\text { test }\end{array}$ & $\begin{array}{l}\text { Sell Scale of Sexual } \\
\text { Orientation, with scores } \\
\text { re-coded into } 4 \\
\text { categories: asexuality, } \\
\text { heterosexuality, } \\
\text { bisexuality, } \\
\text { homosexuality } \\
\text { Proportion of individuals } \\
\text { in categories not } \\
\text { reported }\end{array}$ & $\begin{array}{l}\text {-Higher prevalence of } \\
\text { asexuality found in } \\
\text { autistic relative to } \\
\text { non-autistic adults } \\
\text {-Autistic females } \\
\text { report "lower degree } \\
\text { of heterosexuality" } \\
\text { relative to autistic } \\
\text { males }\end{array}$ \\
\hline
\end{tabular}




\begin{tabular}{|c|c|c|c|c|c|c|c|c|}
\hline$\stackrel{\vec{E}}{\tilde{E}}$ & $\begin{array}{l}\text { Participant } \\
\text { groups, } N s\end{array}$ & $\begin{array}{l}\text { Age, years } \\
\text { Mean (SD), } \\
\text { Range }\end{array}$ & $\begin{array}{l}\text { Sex assigned at } \\
\text { birth (F/M) }\end{array}$ & Gender identity & $\begin{array}{l}\text { Aims/Research } \\
\text { questions related } \\
\text { to sexual } \\
\text { orientation }\end{array}$ & $\begin{array}{l}\text { Methods \& } \\
\text { measures }\end{array}$ & $\begin{array}{l}\text { How Sexual orientation } \\
\text { assessed \& reporting of } \\
\text { sexual orientations }\end{array}$ & Relevant findings \\
\hline 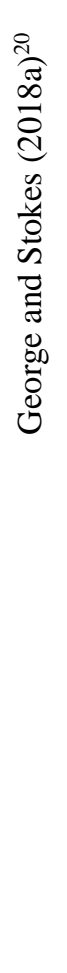 & $\begin{array}{l}\text { Autistic } \\
310 \\
\text { Non-autistic } \\
261\end{array}$ & $\begin{array}{l}\text { Autistic } \\
31.01 \text { (11.37) } \\
\text { Non-Autistic } \\
30.20 \text { (11.92) }\end{array}$ & $\begin{array}{l}\text { Autistic } \\
219 / 90 \\
\text { Non-Autistic } \\
158 / 103\end{array}$ & $\begin{array}{l}\text { Autistic } \\
\text { Cisgender: } 217 \\
\text { Trans female: } 7 \\
\text { Trans male: } 5 \\
\text { Gender queer: } 30 \\
\text { Other: } 32 \\
\text { Non-autistic } \\
\text { Cisgender: } 234 \\
\text { Trans female: } 4 \\
\text { Trans male: } 1 \\
\text { Gender queer: } 8 \\
\text { Other: } 5\end{array}$ & $\begin{array}{l}\text {-Explore } \\
\text { association } \\
\text { between autistic } \\
\text { features and } \\
\text { "gender-dysphoric } \\
\text { traits" in autistic } \\
\text { and non-autistic } \\
\text { adults }\end{array}$ & $\begin{array}{l}\text { Online surveys } \\
\text { - Autism Spectrum } \\
\text { Quotient (AQ) } \\
\text { - Gender-Identity/ } \\
\text { Gender-Dysphoria } \\
\text { Questionnaire for } \\
\text { Adolescents and } \\
\text { Adults } \\
\text { (GIDYQ-AA) }\end{array}$ & $\begin{array}{l}\text { Unclear how sexual } \\
\text { orientation assessed. } \\
\text {-Sexual orientation } \\
\text { coded in } 2 \text { ways for } \\
\text { analyses, either } \\
\text { dichotomously } \\
\text { (heterosexual, non- } \\
\text { heterosexual); or } \\
\text { homosexuality (gay \& } \\
\text { lesbian), bisexuality, } \\
\text { heterosexuality, } \\
\text { asexuality, and other } \\
\text { (transgender, } \\
\text { questioning, pansexual, } \\
\text { intersexual \& other) } \\
\text { Proportion of } \\
\text { participants with sexual } \\
\text { orientation identities not } \\
\text { reported }\end{array}$ & $\begin{array}{l}\text {-“Gender dysphoric } \\
\text { traits" mediated } \\
\text { association between } \\
\text { autistic traits \& } \\
\text { sexual orientation }\end{array}$ \\
\hline
\end{tabular}




\begin{tabular}{|c|c|c|c|c|c|c|c|c|}
\hline$\stackrel{\vec{B}}{\vec{E}}$ & $\begin{array}{l}\text { Participant } \\
\text { groups, } N s\end{array}$ & $\begin{array}{l}\text { Age, years } \\
\text { Mean (SD), } \\
\text { Range }\end{array}$ & $\begin{array}{l}\text { Sex assigned at } \\
\text { birth }(\mathrm{F} / \mathrm{M})\end{array}$ & Gender identity & $\begin{array}{l}\text { Aims/Research } \\
\text { questions related } \\
\text { to sexual } \\
\text { orientation }\end{array}$ & $\begin{array}{l}\text { Methods \& } \\
\text { measures }\end{array}$ & $\begin{array}{l}\text { How Sexual orientation } \\
\text { assessed \& reporting of } \\
\text { sexual orientations }\end{array}$ & Relevant findings \\
\hline 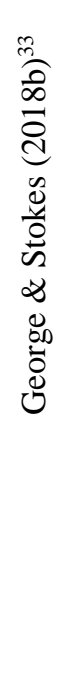 & $\begin{array}{l}\text { Autistic } \\
310 \\
\\
\text { Non-autistic } \\
261\end{array}$ & $\begin{array}{l}\text { Autistic } \\
31.01 \text { (11.37) } \\
\text { Non-Autistic } \\
30.20 \text { (11.92) }\end{array}$ & $\begin{array}{l}\text { Autistic } \\
219 / 90 \\
\\
\text { Non-Autistic } \\
158 / 103\end{array}$ & $\begin{array}{l}\text { Not reported, but } \\
\text { same sample } \\
\text { described in } \\
\text { George \& Stokes } \\
\text { 2018a and } \\
\text { summarized above }\end{array}$ & $\begin{array}{l}\text {-Examine mental } \\
\text { health for autistic } \\
\text { relative to non- } \\
\text { autistic adults; and } \\
\text { sexual minority } \\
\text { relative to non- } \\
\text { sexual-minority } \\
\text { adults } \\
\text {-Examine whether } \\
\text { mental health } \\
\text { impacted by } \\
\text { intersection of } \\
\text { autism status } \\
\text { sexual minority } \\
\text { status }\end{array}$ & $\begin{array}{l}\text { Online surveys } \\
\text {-Depression, } \\
\text { Anxiety, and Stress } \\
\text { Scale-21 (DASS-21) } \\
\text {-Personal Wellbeing } \\
\text { Index (PWI) } \\
\text {-Gender-Identity/ } \\
\text { Gender-Dysphoria } \\
\text { Questionnaire } \\
\text { for Adolescents and } \\
\text { Adults } \\
\text { (GIDYQ-AA) }\end{array}$ & $\begin{array}{l}\text { Using Sell Scale of } \\
\text { Sexual Orientation, } \\
\text { participants grouped into } \\
\text { heterosexual or non- } \\
\text { heterosexual } \\
\text { Proportion of } \\
\text { participants in } \\
\text { heterosexual and non- } \\
\text { heterosexual groups not } \\
\text { reported }\end{array}$ & $\begin{array}{l}\text {-Non-heterosexual } \\
\text { (autistic \& non- } \\
\text { autistic groups } \\
\text { combined) poorer } \\
\text { mental health } \\
\text {-Poorer mental health } \\
\text { in non-autistic sexual } \\
\text { minority relative to } \\
\text { non-autistic } \\
\text { heterosexual } \\
\text {-Mental health did } \\
\text { not differ for autistic } \\
\text { sexual minority vs. } \\
\text { autistic heterosexual }\end{array}$ \\
\hline
\end{tabular}




\begin{tabular}{|c|c|c|c|c|c|c|c|c|}
\hline 突 & $\begin{array}{l}\text { Participant } \\
\text { groups, } N s\end{array}$ & $\begin{array}{l}\text { Age, years } \\
\text { Mean (SD), } \\
\text { Range }\end{array}$ & $\begin{array}{l}\text { Sex assigned at } \\
\text { birth }(\mathrm{F} / \mathrm{M})\end{array}$ & Gender identity & $\begin{array}{l}\text { Aims/Research } \\
\text { questions related } \\
\text { to sexual } \\
\text { orientation }\end{array}$ & $\begin{array}{l}\text { Methods \& } \\
\text { measures }\end{array}$ & $\begin{array}{l}\text { How Sexual orientation } \\
\text { assessed \& reporting of } \\
\text { sexual orientations }\end{array}$ & Relevant findings \\
\hline 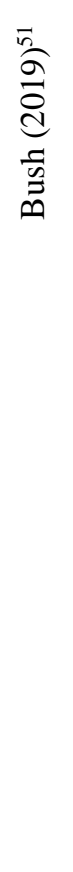 & $\begin{array}{l}\text { Autistic } \\
248 \\
\text { Non-Autistic } \\
179\end{array}$ & $\begin{array}{l}\text { Autistic } \\
23.2 \text { (3.7) } \\
\text { Range: } 18-30 \\
\text { Non-autistic } \\
21.8 \text { (3.5) } \\
\text { Range: } 18-30\end{array}$ & $\begin{array}{l}\text { All participants } \\
\text { assigned female } \\
\text { at birth }\end{array}$ & $\begin{array}{l}\text { Autistic } \\
\text { Agender: } 42 \\
\text { Genderqueer or } \\
\text { non-binary: } 37 \\
\text { Demigirl: } 17 \\
\text { Genderfluid: } 9 \\
\text { Non-Autistic } \\
\text { Agender: } 11 \\
\text { Genderqueer or } \\
\text { non-binary: } 12 \\
\text { Demigirl: } 5 \\
\text { Genderfluid: } 5\end{array}$ & $\begin{array}{l}\text {-Examine autistic } \\
\text { and non-autistic } \\
\text { females across } \\
\text { domains of sexual } \\
\text { experiences, } \\
\text { behaviors, desire, } \\
\text { satisfaction, and } \\
\text { awareness }\end{array}$ & $\begin{array}{l}\text { Online Surveys } \\
\text { - 10-item Autism } \\
\text { Spectrum Quotient } \\
\text { (AQ-10) } \\
\text { - Sexual History } \\
\text { Questionnaire } \\
\text { (SHQ) } \\
\text { - Sexual Desire } \\
\text { Inventory (SDI) } \\
\text { - Sexual Experience } \\
\text { Questionnaire } \\
\text { - Sexual Satisfaction } \\
\text { Scale for Women } \\
\text { (SSSW) } \\
\text { - Sexual Awareness } \\
\text { Questionnaire } \\
\text { (SAQ) }\end{array}$ & $\begin{array}{l}\text { Open-ended question } \\
\text { (question wording not } \\
\text { available) } \\
\text { Autistic } \\
\text { Asexual: 13\% } \\
\text { Bisexual: 12\% } \\
\text { Pansexual/ } \\
\text { Polysexual: 12\% } \\
\text { Queer: 10\% } \\
\text { Heterosexual: 8\% } \\
\text { Non-autistic } \\
\text { Asexual: 11\% } \\
\text { Bisexual: 27\% } \\
\text { Pansexual/ } \\
\text { Polysexual: } 8 \% \\
\text { Queer: 4\% } \\
\text { Heterosexual: 28\% }\end{array}$ & $\begin{array}{l}\text {-Autistic females } \\
\text { more likely to report } \\
\text { sexual minority } \\
\text { identity (non- } \\
\text { heterosexual) relative } \\
\text { to non-autistic } \\
\text { women }\end{array}$ \\
\hline
\end{tabular}




\begin{tabular}{|c|c|c|c|c|c|c|c|c|}
\hline $\begin{array}{l}\overrightarrow{0} \\
\stackrel{\Xi}{\tilde{E}}\end{array}$ & $\begin{array}{l}\text { Participant } \\
\text { groups, } N s\end{array}$ & $\begin{array}{l}\text { Age, years } \\
\text { Mean (SD), } \\
\text { Range }\end{array}$ & $\begin{array}{l}\text { Sex assigned at } \\
\text { birth }(F / M)\end{array}$ & Gender identity & $\begin{array}{l}\text { Aims/Research } \\
\text { questions related } \\
\text { to sexual } \\
\text { orientation }\end{array}$ & $\begin{array}{l}\text { Methods \& } \\
\text { measures }\end{array}$ & $\begin{array}{l}\text { How Sexual orientation } \\
\text { assessed \& reporting of } \\
\text { sexual orientations }\end{array}$ & Relevant findings \\
\hline 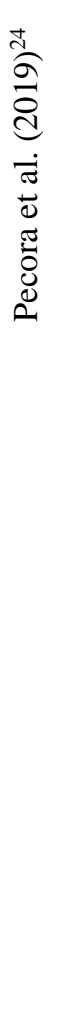 & $\begin{array}{l}\text { Autistic } \\
231 \\
\text { Non-autistic } \\
227\end{array}$ & $\begin{array}{l}\text { Autistic } \\
25.13(7.96) \\
\text { Non-autistic } \\
22.16(5.25)\end{array}$ & $\begin{array}{l}\text { Autistic } \\
135 / 96 \\
\\
\text { Non-autistic } \\
161 / 66\end{array}$ & $\begin{array}{l}\text { Autistic } \\
\text { Female: } 111 \\
\text { Male: } 95 \\
\text { Other: } 26 \\
\\
\text { Non-autistic } \\
\text { Female: } 152 \\
\text { Male: } 62 \\
\text { Other: } 12\end{array}$ & $\begin{array}{l}\text {-Examine sexual } \\
\text { interests, behaviors, } \\
\& \text { negative sexual } \\
\text { experiences in } \\
\text { autistic females } \\
\text { compared to } \\
\text { autistic males and } \\
\text { to non-autistic } \\
\text { females }\end{array}$ & $\begin{array}{l}\text { Online Surveys } \\
\text { - Autism Spectrum } \\
\text { Quotient (50-item) } \\
\text { - 25-item modified } \\
\text { sexual behavior (SB) } \\
\text { subscale derived } \\
\text { from the } \\
\text { Sexual Behavior } \\
\text { Scale: Version } 3 \\
\text { (SBS-III) }\end{array}$ & $\begin{array}{l}\text { Unclear how sexual } \\
\text { orientation assessed. } \\
\text { Autistic female } \\
\text { Heterosexual: } 31.1 \% \\
\text { Homosexual: } 43.7 \% \\
\text { Bisexual: } 25.2 \% \\
\text { Autistic male } \\
\text { Heterosexual: } 58.8 \% \\
\text { Homosexual: } 22.6 \% \\
\text { Bisexual: } 18.6 \% \\
\text { Non-autistic female } \\
\text { Heterosexual: } 54.4 \% \\
\text { Homosexual: } 28.6 \% \\
\text { Bisexual: } 16.9 \% \\
\text { Non-autistic male } \\
\text { Heterosexual: } 56.7 \% \\
\text { Homosexual: } 26.9 \% \\
\text { Bisexual: } 16.4 \%\end{array}$ & $\begin{array}{l}\text { - Larger proportion of } \\
\text { autistic females } \\
\text { reported non- } \\
\text { heterosexual } \\
\text { orientation than either } \\
\text { autistic males or non- } \\
\text { autistic females }\end{array}$ \\
\hline
\end{tabular}




\begin{tabular}{|c|c|c|c|c|c|c|c|c|}
\hline$\frac{\overrightarrow{0}}{\vec{D}}$ & $\begin{array}{l}\text { Participant } \\
\text { groups, } N s\end{array}$ & $\begin{array}{l}\text { Age, years } \\
\text { Mean (SD), } \\
\text { Range }\end{array}$ & $\begin{array}{l}\text { Sex assigned at } \\
\text { birth }(F / M)\end{array}$ & Gender identity & $\begin{array}{l}\text { Aims/Research } \\
\text { questions related } \\
\text { to sexual } \\
\text { orientation }\end{array}$ & $\begin{array}{l}\text { Methods \& } \\
\text { measures }\end{array}$ & $\begin{array}{l}\text { How Sexual orientation } \\
\text { assessed \& reporting of } \\
\text { sexual orientations }\end{array}$ & Relevant findings \\
\hline 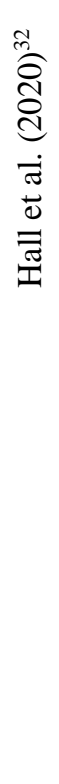 & $\begin{array}{l}\text { Autistic \& } \\
\text { LGBTQ+ } \\
19 \\
\text { Autistic \& } \\
\text { Non- } \\
\text { LGBTQ+ } \\
35\end{array}$ & $\begin{array}{l}\text { Autistic } \\
\text { LGBTQ+: } \\
31.1 \\
\text { Range: } 20-49 \\
\\
\text { Autistic Non- } \\
\text { LGBTQ+ } \\
30.2 \\
\text { Range: } 18-58\end{array}$ & Not reported & $\begin{array}{l}\text { Autistic LGBTQ+ } \\
\text { Female: } 7 \\
\text { Male: } 5 \\
\text { Other: } 7 \\
\text { Autistic } \\
\text { Non-LGBTQ+ } \\
\text { Female: } 14 \\
\text { Male: } 21 \\
\text { Other: } 0\end{array}$ & $\begin{array}{l}\text {-Examine health in } \\
\text { autistic LGBTQ+ } \\
\text { compared to } \\
\text { autistic non- } \\
\text { LGBTQ+ }\end{array}$ & $\begin{array}{l}\text { Online surveys } \\
\text { - Behavioral Risk } \\
\text { Factor Surveillance } \\
\text { System (BRFSS) } \\
\text { - National Health } \\
\text { Interview Survey } \\
\text { (NHIS) } \\
\text { - Health Reform } \\
\text { Monitoring Survey } \\
\text { (HRMS) }\end{array}$ & $\begin{array}{l}\text { NHIS item: "Do you } \\
\text { think of yourself as" } \\
\text { Response options: } \\
\text { "Gay or lesbian; } \\
\text { Straight, that is not gay } \\
\text { or lesbian; Bisexual; } \\
\text { Something else; I don't } \\
\text { know the answer" } \\
\text {-35\% of autistic } \\
\text { participants identified as } \\
\text { LGBTQ+ ; frequencies } \\
\text { of specific identities not } \\
\text { reported }\end{array}$ & $\begin{array}{l}\text { - } 78.9 \% \text { of LGBTQ+ } \\
\text { reported mental } \\
\text { illness, relative to } \\
34.3 \% \text { of non- } \\
\text { LGBTQ+ participants } \\
\text { - } 47.4 \% \text { LGBTQ+ } \\
\text { reported chronic } \\
\text { illness, relative to } \\
31.4 \% \text { of non- } \\
\text { LGBTQ+ participants } \\
\text {-LGBTQ+ face } \\
\text { barriers to health care } \\
\text { and have more unmet } \\
\text { health needs relative } \\
\text { to } \\
\text { to non-LGBTQ } \\
\text { participants }\end{array}$ \\
\hline
\end{tabular}




\begin{tabular}{|c|c|c|c|c|c|c|c|c|}
\hline$\frac{B}{E}$ & $\begin{array}{l}\text { Participant } \\
\text { groups, } N s\end{array}$ & $\begin{array}{l}\text { Age, years } \\
\text { Mean (SD), } \\
\text { Range }\end{array}$ & $\begin{array}{l}\text { Sex assigned at } \\
\text { birth }(\mathrm{F} / \mathrm{M})\end{array}$ & Gender identity & $\begin{array}{l}\text { Aims/Research } \\
\text { questions related } \\
\text { to sexual } \\
\text { orientation }\end{array}$ & $\begin{array}{l}\text { Methods \& } \\
\text { measures }\end{array}$ & $\begin{array}{l}\text { How Sexual orientation } \\
\text { assessed \& reporting of } \\
\text { sexual orientations }\end{array}$ & Relevant findings \\
\hline 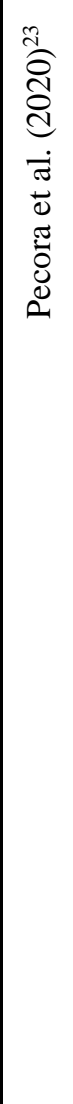 & $\begin{array}{l}\text { Autistic } \\
134 \\
\text { Non-autistic } \\
161\end{array}$ & $\begin{array}{l}\text { Autistic } \\
26.2 \text { (8.7) } \\
\text { Range: 18-56 } \\
\text { Non-autistic } \\
22 \text { (4.6) } \\
\text { Range: } 18-48\end{array}$ & $\begin{array}{l}\text { All participants } \\
\text { assigned female } \\
\text { at birth }\end{array}$ & $\begin{array}{l}\text { Autistic } \\
\text { Female: } 108 \\
\text { Male: } 4 \\
\text { Other: } 22 \\
\text { Non-autistic } \\
\text { Female: } 147 \\
\text { Male: } 2 \\
\text { Other: } 12\end{array}$ & $\begin{array}{l}\text { - Examine } \\
\text { prevalence of non- } \\
\text { heterosexual } \\
\text { orientation and/or } \\
\text { transgender identity } \\
\text { in autistic and non- } \\
\text { autistic females } \\
\text { - Examine negative } \\
\text { sexual encounters } \\
\text { and/or } \\
\text { victimization in } \\
\text { sexual minority } \\
\text { and/or transgender } \\
\text { autistic females and } \\
\text { non-autistic } \\
\text { females }\end{array}$ & $\begin{array}{l}\text { Online surveys } \\
\text { - Autism Spectrum } \\
\text { Quotient (50-item) } \\
\text { - The Sexual } \\
\text { Behavior Scale, } \\
\text { Version } 3 \text { (SBS-III) }\end{array}$ & $\begin{array}{l}\text { SBS-III item: } \\
\text { "I consider my sexual } \\
\text { orientation to be" } \\
\text { Response options: } \\
\text { "Heterosexual; } \\
\text { Homosexual; Bisexual; } \\
\text { Asexual; Transattracted; } \\
\text { Questioning" } \\
\text { Autistic } \\
\text { Heterosexual: } 30.6 \% \\
\text { Homosexual: } 44.0 \% \\
\text { Bisexual: 25.4\% } \\
\text { Asexual: 0\% } \\
\text { Transattracted: } 0 \% \\
\text { Questioning: } 0 \% \\
\text { Non-autistic } \\
\text { Heterosexual: } 54.6 \% \\
\text { Homosexual: } 28.6 \% \\
\text { Bisexual: } 16.8 \% \\
\text { Asexual: } 0 \% \\
\text { Transattracted: } 0 \% \\
\text { Questioning: } 0 \%\end{array}$ & $\begin{array}{l}\text { - Autistic females } \\
\text { more likely to report } \\
\text { sexual minority } \\
\text { identity than non- } \\
\text { autistic females } \\
\text { - Autistic females } \\
\text { more likely to } \\
\text { identify with non- } \\
\text { heterosexual sexual } \\
\text { identity than non- } \\
\text { autistic peers }\end{array}$ \\
\hline
\end{tabular}




\begin{tabular}{|c|c|c|c|c|c|c|c|c|}
\hline$\frac{\vec{\theta}}{\vec{E}}$ & $\begin{array}{l}\text { Participant } \\
\text { groups, } N s\end{array}$ & $\begin{array}{l}\text { Age, years } \\
\text { Mean (SD), } \\
\text { Range }\end{array}$ & $\begin{array}{l}\text { Sex assigned at } \\
\text { birth }(\mathrm{F} / \mathrm{M})\end{array}$ & Gender identity & $\begin{array}{l}\text { Aims/Research } \\
\text { questions related } \\
\text { to sexual } \\
\text { orientation }\end{array}$ & $\begin{array}{l}\text { Methods \& } \\
\text { measures }\end{array}$ & $\begin{array}{l}\text { How Sexual orientation } \\
\text { assessed \& reporting of } \\
\text { sexual orientations }\end{array}$ & Relevant findings \\
\hline 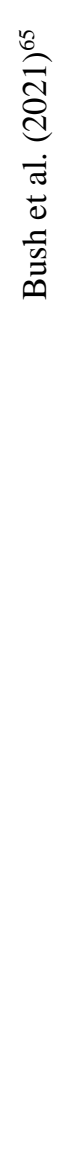 & $\begin{array}{l}\text { Autistic } \\
247\end{array}$ & $\begin{array}{l}23.2(3.7) \\
\text { Range: } 18-30\end{array}$ & $\begin{array}{l}\text {-All participants } \\
\text { assigned female } \\
\text { at birth } \\
\text {-Included } \\
\text { participants } \\
\text { identified as a } \\
\text { woman or as a } \\
\text { non-male gender } \\
\text { identity (e.g., } \\
\text { agender, } \\
\text { nonbinary) }\end{array}$ & $\begin{array}{l}\text { Agender: } 17 \% \\
(n=42) \\
\text { Genderqueer or } \\
\text { non- } \\
\text { binary: } 15 \% \text { : } \\
(n=37) \\
\text { Demigirl: } 7 \% \\
(n=17) \\
\text { Genderfluid: } 4 \% \\
(n=9)\end{array}$ & $\begin{array}{l}\text { Identify differences } \\
\text { in demographics, } \\
\text { sexuality \& } \\
\text { internalizing } \\
\text { symptoms between } \\
\text { asexual spectrum } \\
\text { autistic adults and } \\
\text { autistic adults not } \\
\text { on the asexual } \\
\text { spectrum }\end{array}$ & $\begin{array}{l}\text { Online surveys } \\
\text { - 10-item Autism } \\
\text { Spectrum Quotient } \\
\text { (AQ-10) } \\
\text { - Sexual History } \\
\text { Questionnaire (SEQ) } \\
\text { - Sexual Desire } \\
\text { Inventory (SDI) } \\
\text {-Sexual Satisfaction } \\
\text { Scale for Women } \\
\text { - Personal Health } \\
\text { Questionnaire } \\
\text { Depression Scale } \\
\text { - Generalized } \\
\text { Anxiety Disorder } \\
\text { Scale (GAD-7) } \\
\text {-Mini-Social Phobia } \\
\text { Inventory }\end{array}$ & $\begin{array}{l}\text { Open-ended question: } \\
\text { "In your own words, } \\
\text { how would you describe } \\
\text { your sexual orientation? } \\
\text { Examples might include, } \\
\text { 'straight', 'lesbian,' } \\
\text { 'bisexual,' 'queer,' etc." } \\
\text { Responses consensus } \\
\text { coded; participants } \\
\text { grouped into "asexual } \\
\text { spectrum," and "other } \\
\text { sexual orientations," } \\
\text { where "other" included } \\
\text { gay, bisexual and } \\
\text { heterosexual } \\
\text { 36\% of participants on } \\
\text { the "asexual spectrum" } \\
\text { Asexual: } 59 \\
\text { Questioning asexual: } 9 \\
\text { Gray-asexual: } 7 \\
\text { Demisexual: } 7 \\
\text { Otherwise on asexual } \\
\text { spectrum: } 6\end{array}$ & $\begin{array}{l}\text {-Compared to "other" } \\
\text { sexual identities, } \\
\text { asexual autistic adults } \\
\text { reported less } \\
\text { generalized anxiety, } \\
\text { but comparable levels } \\
\text { of depression and } \\
\text { social anxiety }\end{array}$ \\
\hline
\end{tabular}




\begin{tabular}{|c|c|c|c|c|c|c|c|c|}
\hline है & $\begin{array}{l}\text { Participant } \\
\text { groups, } N s\end{array}$ & $\begin{array}{l}\text { Age, years } \\
\text { Mean (SD), } \\
\text { Range }\end{array}$ & $\begin{array}{l}\text { Sex assigned at } \\
\text { birth }(\mathrm{F} / \mathrm{M})\end{array}$ & Gender identity & $\begin{array}{l}\text { Aims/Research } \\
\text { questions related } \\
\text { to sexual } \\
\text { orientation }\end{array}$ & $\begin{array}{l}\text { Methods \& } \\
\text { measures }\end{array}$ & $\begin{array}{l}\text { How Sexual orientation } \\
\text { assessed \& reporting of } \\
\text { sexual orientations }\end{array}$ & Relevant findings \\
\hline 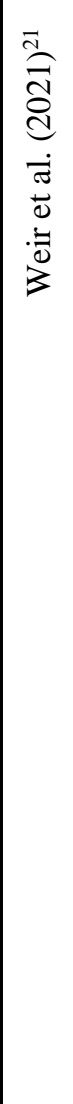 & $\begin{array}{l}\text { Autistic } \\
1183 \\
\text { Non-autistic } \\
1203\end{array}$ & $\begin{array}{l}\text { Autistic } \\
41.04 \text { (14.41) } \\
\text { Non-autistic } \\
41.86 \text { (15.59) } \\
\text { Full sample } \\
\text { age range: 16- } \\
90\end{array}$ & $\begin{array}{l}\text { Autistic } \\
437 / 746 \\
\text { Non-autistic } \\
\text { F: } 825 \\
\text { M: } 378\end{array}$ & $\begin{array}{l}\text { Autistic } \\
\text { Cisgender: } 1031 \\
\text { Transgender: } 149 \\
\text { Missing: } 3 \\
\text { Non-Autistic } \\
\text { Cisgender: } 1178 \\
\text { Transgender: } 24 \\
\text { Missing: } 1\end{array}$ & $\begin{array}{l}\text { Examine sexuality } \\
\text { and sexual activity } \\
\text { experience in } \\
\text { autistic and non- } \\
\text { autistic individuals } \\
\text { from a lifespan } \\
\text { perspective }\end{array}$ & $\begin{array}{l}\text { Online surveys } \\
\text { - Autism Spectrum } \\
\text { Quotient (AQ-10) } \\
\text { - questions about } \\
\text { lifestyle-related } \\
\text { factors, personal } \\
\text { medical history, and } \\
\text { family medical } \\
\text { history, as part of } \\
\text { the Autism and } \\
\text { Physical Health } \\
\text { Survey (APHS) }\end{array}$ & $\begin{array}{l}\text { Multiple choice } \\
\text { question: } \\
\text { "Which one of the } \\
\text { following best describes } \\
\text { your sexual orientation?" } \\
\text { Response options: } \\
\text { "Heterosexual; } \\
\text { Homosexual; Bisexual; } \\
\text { Asexual; Other" } \\
\text { Autistic } \\
\text { Heterosexual: } 63.03 \% \\
\text { Homosexual: } 7.3 \% \\
\text { Bisexual: } 13 . \% \\
\text { Asexual: } 10.05 \% \\
\text { Other: } 5.71 \\
\text { Non-autistic } \\
\text { Heterosexual: } 83.08 \% \\
\text { Homosexual: } 4.36 \\
\text { Bisexual: } 10.2 \% \\
\text { Asexual: } 1.51 \% \\
\text { Other: } 0.84 \%\end{array}$ & $\begin{array}{l}\text { - Autistic } \\
\text { adolescents/adults } \\
\text { more likely to have } \\
\text { more diverse (e.g., } \\
\text { bisexual, asexual) } \\
\text { sexual orientations } \\
\text { relative to non- } \\
\text { autistic } \\
\text { adolescents/adults } \\
\text {-Autistic males more } \\
\text { likely to identify as } \\
\text { "bisexual" compared } \\
\text { to non-autistic males } \\
\text {-Autistic females } \\
\text { more likely to } \\
\text { identify as } \\
\text { "homosexual" than } \\
\text { non-autistic females } \\
\text { - Autistic females } \\
\text { more diverse sexual } \\
\text { orientations than } \\
\text { autistic males for all } \\
\text { categories except } \\
\text { "homosexual" }\end{array}$ \\
\hline
\end{tabular}


Table 2. Participant Characteristics: Descriptive Statistics and Comparisons of Heterosexual and Sexual Minority Groups

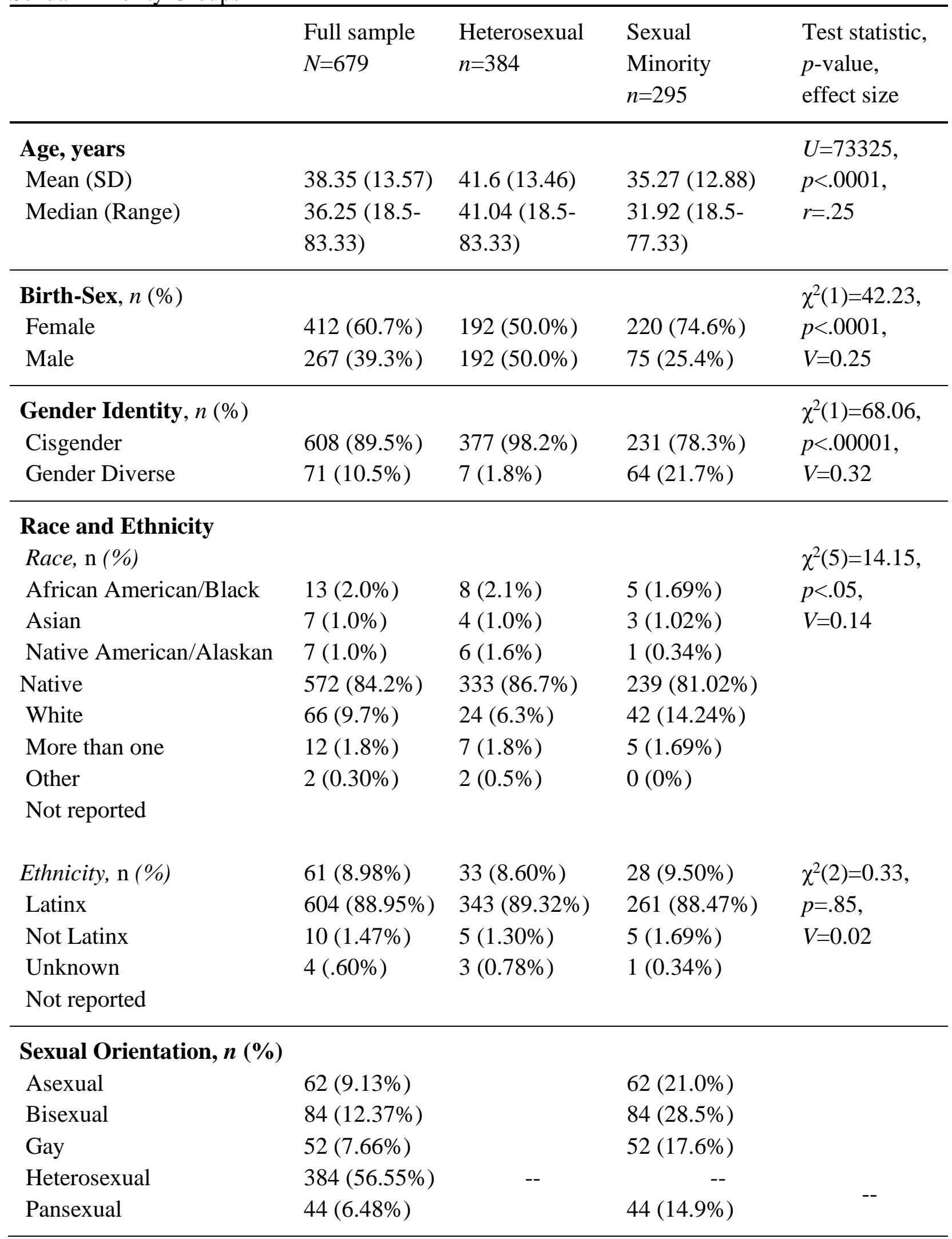




\begin{tabular}{|c|c|c|c|c|}
\hline Queer & $16(2.36 \%)$ & & $16(5.4 \%)$ & \\
\hline Other & $10(1.47 \%)$ & & $10(3.4 \%)$ & \\
\hline Do not know & $27(3.98 \%)$ & & $27(9.2 \%)$ & \\
\hline Household Income, $n$ (\%) & & & & \multirow{12}{*}{$\begin{array}{l}\chi^{2}(10)=25.96, \\
p<.01 \\
V=0.20\end{array}$} \\
\hline$<\$ 20,000$ & $198(29.20 \%)$ & $105(27.34 \%)$ & $93(31.52 \%)$ & \\
\hline$\$ 21,000-\$ 35,000$ & $107(15.80 \%)$ & $51(13.28 \%)$ & $56(18.98 \%)$ & \\
\hline$\$ 36,000-\$ 50,000$ & $78(11.50 \%)$ & $43(11.20 \%)$ & $35(11.86 \%)$ & \\
\hline$\$ 51,000-\$ 65,000$ & $48(7.10 \%)$ & $33(8.59 \%)$ & $15(5.10 \%)$ & \\
\hline$\$ 66,000-\$ 80,000$ & $44(6.50 \%)$ & $25(6.51 \%)$ & $19(6.44 \%)$ & \\
\hline$\$ 81,000-\$ 100,000$ & $41(6.0 \%)$ & $29(7.55 \%)$ & $12(4.07 \%)$ & \\
\hline$\$ 101,000-\$ 130,000$ & $40(6.0 \%)$ & $30(7.81 \%)$ & $10(3.39 \%)$ & \\
\hline$\$ 131,000-\$ 160,000$ & $23(3.40 \%)$ & $16(4.17 \%)$ & $7(2.37 \%)$ & \\
\hline$\$ 161,000+$ & $31(4.60 \%)$ & $21(5.47 \%)$ & $10(3.39 \%)$ & \\
\hline Don’t know & $45(6.60 \%)$ & $17(4.43 \%)$ & $28(9.49 \%)$ & \\
\hline Prefer not to answer & $24(3.50 \%)$ & $14(3.65 \%)$ & $10(3.39 \%)$ & \\
\hline \multicolumn{4}{|l|}{ AQ-28 } & \multirow{3}{*}{$\begin{array}{l}t(677)=-0.97, \\
p=.33 \\
d=-0.08\end{array}$} \\
\hline Mean (SD) & $84.42(11.55)$ & $84.04(11.55)$ & 84.91 (11.6) & \\
\hline Median (Range) & $85(47-112)$ & $85(47-110)$ & $85(49-112)$ & \\
\hline \multirow{3}{*}{$\begin{array}{l}\text { Met AQ-28 Screening } \\
\text { Cut-off, } \boldsymbol{n}(\%) \\
\text { Yes } \\
\text { No }\end{array}$} & $644(94.8 \%)$ & $363(94.5 \%)$ & $281(95.3 \%)$ & \multirow{3}{*}{$\begin{array}{l}\chi^{2}(1)=0.06 \\
p=.80 \\
V=0.02\end{array}$} \\
\hline & $35(5.2 \%)$ & $21(5.5 \%)$ & $14(4.7 \%)$ & \\
\hline & & & & \\
\hline
\end{tabular}

Notes: Participants reported on their gender identity in response to the question "What is your gender?" Participants could select one or more of the following: 'female,' 'male,' 'trans female,' 'trans male,' 'gender, non-conforming,' 'gender queer,' 'another gender identity.' Here, gender diverse designates individuals who reported gender identity other than the sex assigned at birth and cisgender designates those who reported a gender identity identical to their sex assigned at birth. AQ-28=28-item Autism-Spectrum Quotient 


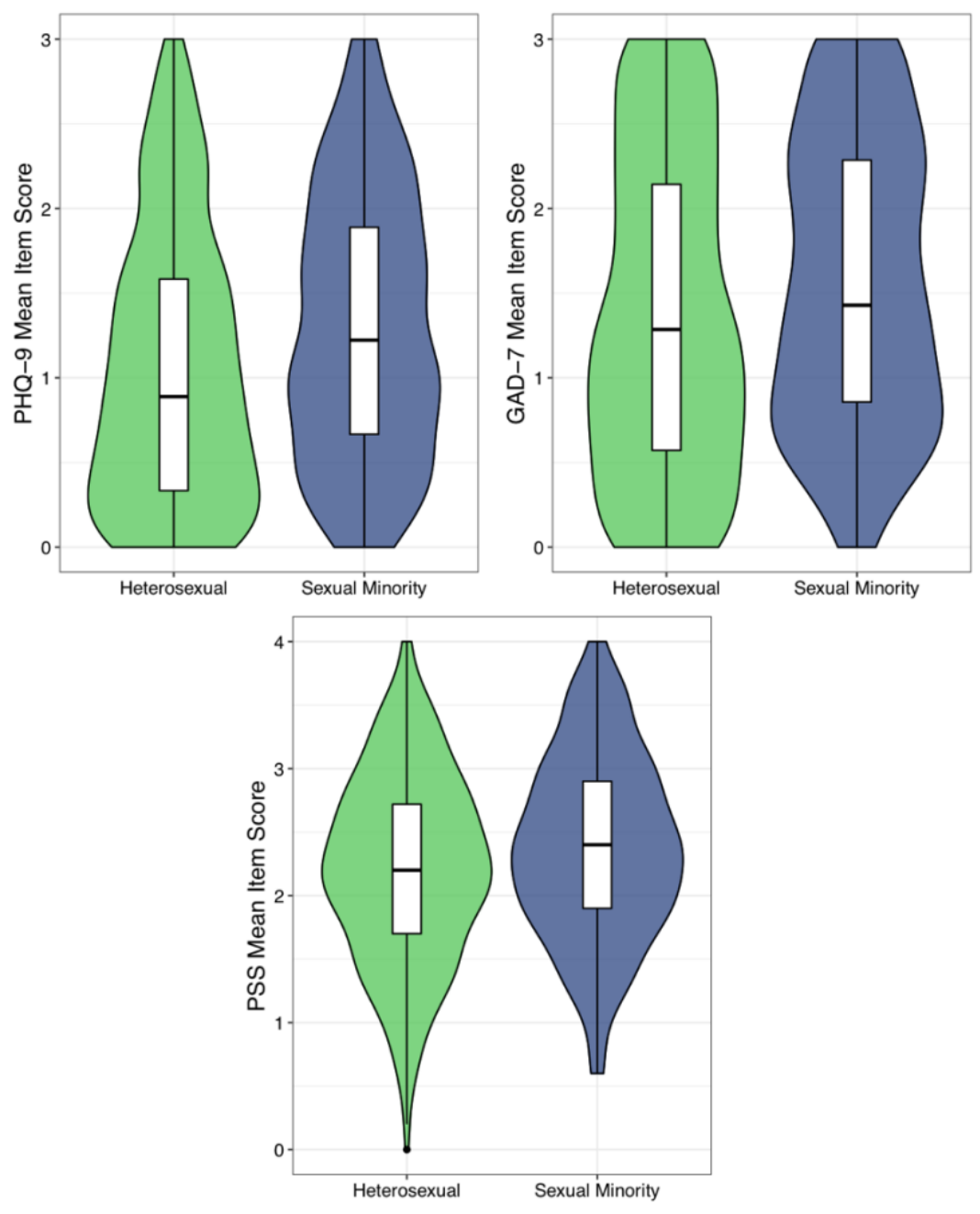

Figure 1. Violin plots showing mean item scores for depressive (PHQ-9) and anxious (GAD-7) symptomatology, and perceived stress (PSS). Minimum and maximum values on the y-axis reflect the minimum and maximum item-level values on the respective measures. 

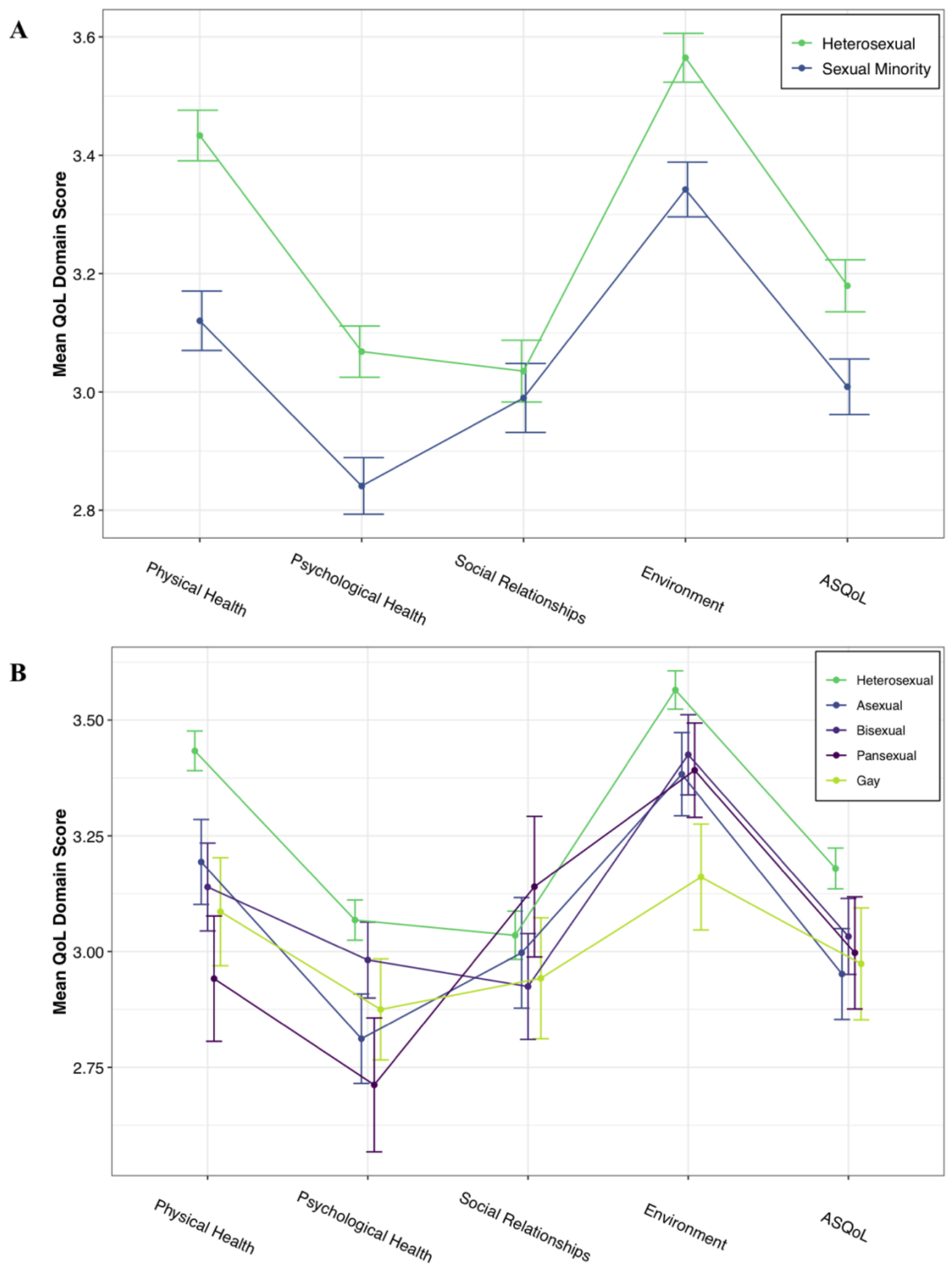

Figure 2. Mean item scores for WHOQOL-BREF domains (Physical Health, Psychological Health, Social Relationships and Environment) and ASQoL for heterosexual and sexual minority 
groups (Panel A); and for heterosexual, gay, asexual, pansexual and bisexual sexual minority identities (Panel B). Error bars represent standard error of the mean. 


\section{Supplement}

Mental health and quality of life (QoL): Analyses separated by sex assigned at birth

Female birth-sex is overrepresented in the sexual minority group (74.6\% of the sexual minority group is female, compared to the heterosexual group in which $50 \%$ are assigned female at birth) (Figure S1). Follow-up exploratory analyses compared sexual minority and heterosexual individuals separately for those assigned female at birth and those assigned male at birth. Notably, and as reported in the main text, no significant sexual orientation group $\times$ birth-sex interactions were found $(p s>.05)$ in any of the models.

Mental health: Autistic adults assigned female at birth

Among autistic adults assigned female sex at birth, sexual minority adults reported elevated depressive symptomatology compared to heterosexual adults $(F(1,407)=6.16, q=.04$, $\eta^{2} p=0.02$ ), but sexual orientation groups did not significantly differ for anxiety symptomatology

$\left(F(1,407)=0.02, q=0.90, \eta^{2} \mathrm{p}=0.00004\right)$, or perceived stress $\left(F(1,407)=0.79, q=0.56, \eta^{2} \mathrm{p}=0.002\right)$.

\section{Mental health: Autistic adults assigned male at birth}

Among autistic adults assigned male sex at birth, sexual minority adults did not significantly differ from heterosexual adults for any of depressive symptomatology

$\left(F(1,260)=0.64, q=0.56, \eta^{2} \mathrm{p}=0.002\right)$, anxiety symptomatology $(F(1,260)=2.63, q=0.32$, $\left.\eta^{2} \mathrm{p}=0.01\right)$, or perceived stress $\left(F(1,260)=0.35, q=0.56, \eta^{2} p=0.001\right)$.

Subjective quality of life (QoL): Autistic adults assigned female at birth 
Using Pillai's Trace, the MANCOVA for females revealed a significant main effect of sexual orientation group (sexual minority vs. heterosexual) on QoL $(F(5,403)=2.99, p=.01$, $V=0.04$ ). Five follow-up ANCOVAs (FDR-corrected, $q<.05$ ) revealed that, compared to heterosexual autistic adults, sexual minority autistic adults reported significantly lower QoL in Physical Health $\left(F(1,407)=12.69, q=.002, \eta^{2} \mathrm{p}=0.03\right)$ and Psychological Health $(F(1,407)=6.95$, $\left.q=.02, \eta^{2} \mathrm{p}=0.01\right)$

Sexual orientation groups for autistic females did not significantly differ for Social Relationships $\left(F(1,407)=0.46, q=0.50, \eta^{2} \mathrm{p}=0.002\right)$, Environment $(F(1,407)=4.24, q=0.07$, $\left.\eta^{2} \mathrm{p}=0.007\right)$, or for Autism-related QoL $\left(F(1,407)=1.45, q=0.29, \eta^{2} \mathrm{p}=0.005\right)$.

\section{QoL: Autistic adults assigned male at birth}

Using Pillai's Trace, the MANCOVA revealed no significant main effect of sexual orientation group on QoL for autistic adults assigned male at birth $(F(5,256)=2.02, p=0.08$, $V=0.04)$.

Summary of exploratory analyses separated by sex assigned at birth

After controlling for age, race and household income, and correcting for multiple comparisons, ANCOVAs examining mental health showed significantly greater depressive symptomatology (but not anxious symptomatology or perceived stress) for sexual minority autistic adults assigned female at birth compared to heterosexual autistic adults assigned female at birth. No significant differences in mental health were noted for sexual orientation groups assigned male at birth. Of note, however, in the main analyses (reported in the text) effect sizes for mental health variables were relatively small, with the largest effect for depressive 
symptomatology. Thus, it is possible that when separating groups by sex assigned at birth these analyses were underpowered to detect these relatively small effects.

The MANCOVA results for those assigned female at birth were similar to those reported in the main text in that both analyses revealed significant sexual orientation group (sexual minority vs. heterosexual) differences, with lower Physical Health and Psychological Health QoL for the sexual minority group. Also in line with analyses reported in the main text, no significant sexual orientation group differences were found for Social Relationships QoL for either those assigned female or male at birth. In the analyses for those assigned female at birth, lower Environment and Autism-related QoL in the sexual minority group did not survive corrections for multiple comparisons, differing from analyses reported in the main text. Of note, however, the QoL MANCOVA effect sizes for both those assigned female at birth and those assigned male at birth were comparable to the effect sizes in the analyses reported in the main text (i.e., the analyses including all sexual minority adults regardless of sex assigned birth). 

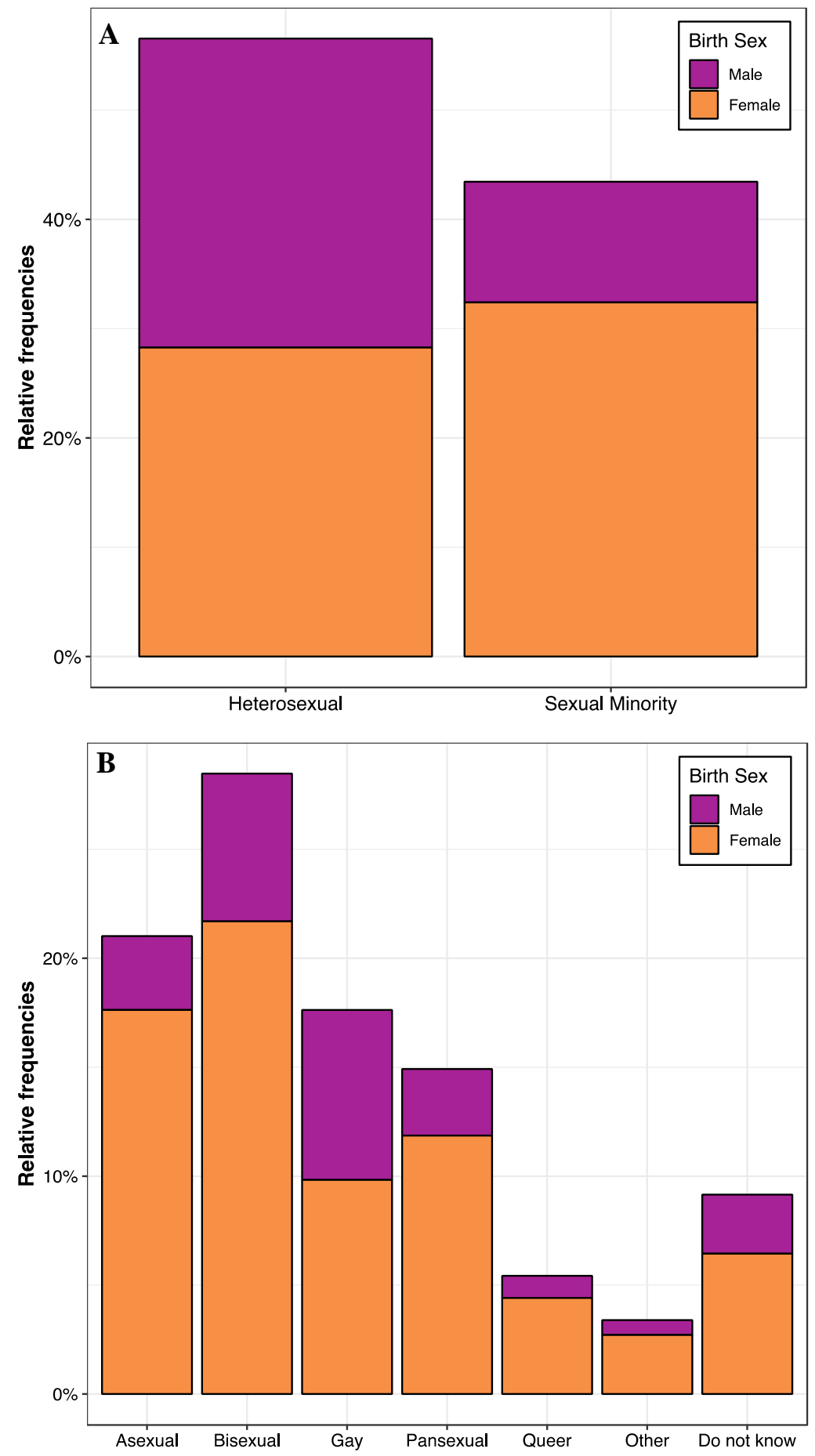

Figure S1. Relative frequencies of autistic adults with sexual minority and heterosexual identities (A), and within the sexual minority group (B), by sex assigned at birth. 